\title{
EXPERIMENTAL AND NUMERICAL STUDY OF STRAIN PROGRESS DURING AND AFTER RIVETING PROCESS FOR BRAZIER RIVET AND RIVET WITH COMPENSATOR - SQUEEZING FORCE AND RIVET TYPE EFFECT
}

\author{
Wojciech Wronicz \\ Jerzy Kaniowski \\ Institute of Aviation, Warsaw, Poland
}

\begin{abstract}
The paper presents the experimental and numerical investigation of the stress and strain field around the rivet after the riveting process. The measurements were carried out with the X-ray diffractometer and strain gauges on the sheet surface near the driven head. The axisymmetric and $3 D$ FEM analyses of the riveting process were performed.

The article presents experimental and numerical results for two types of the brazier rivets used in the Polish aerospace industry; the normal rivet (BN-70/1121-06) and the rivet with a compensator (OST 1 34040-79 1). Bare sheets made from 2024 T3 aluminium alloy with the nominal thickness of 1,27 $\mathrm{mm}$ and rivets with the diameter of $3 \mathrm{~mm}$ and 3,5 $\mathrm{mm}$ made from Polish aluminium alloy PA25 were used. The measurements were compared with the FEM calculations. The influence of squeezing force as well as the rivet type on stress and the strain system was investigated.
\end{abstract}

\section{INTRODUCTION}

In aluminium aircraft structures, the riveting process induces high stresses in sheets. Typically, these stresses exceed the yield point near the rivet hole [1], [2]. This stress system is modified by external loading during operation. Total stress value in sheets as well as its progress are crucial for fatigue properties since fatigue cracks initiate in this area. Stresses induced in the riveting process make up the largest part of total stress. An investigation of the stress system after riveting as well as the influence of the process parameters, rivet types and joint geometry on the stress system are vital for improving fatigue performance of riveted joints as well as accuracy of their fatigue life estimation.

The effect of squeezing force on joint fatigue life has been studied by many researchers, e.g. Müller [1]. Higher squeezing force results in a better filling of the rivet hole, higher clamping force in sheets (which increases load transfer by friction), higher radial expansion of the rivet shank and a larger size of the driven head. Residual stresses resulting from rivet upsetting are compression radial stresses and, for some range of squeezing force, compression tangential stresses in the hole vicinity [1]. Increasing squeezing force enhances fatigue life of the joint because it changes the tangential stress sign - from tension to compression, which prevents cracks nucleation.

Müller has proposed riveting with force control. For the three-raw lap joint, this modification has increased fatigue life from 39630 cycles for low force to 95200 cycles for nominal force and 
446413 cycles for high force. Owing to an increase in squeezing force, the author has obtained an 11 -fold increase in fatigue life and shift of the location of cracks nucleation from the hole edge (invisible) towards the edge of the driven head or the manufactured head.

After the riveting process, radial expansion near the manufactured head is lower than near the driven head, which is unfavourable from the fatigue point of view due to lower residual stresses in this area. Rivets with compensators were developed to correct this problem. Compared to normal rivets, rivets with compensators provide a better hole filling and a higher radial expansion in the sheet at the manufactured head's side. This results in higher residual stresses and longer fatigue life.

Investigation of fatigue life of specimens with rivets with compensators, made of 2024-T3 alloy, was carried out by Simenz [3] among others. Fatigue life of specimens with normal rivets was 55800 cycles, while fatigue life of specimens with rivets with compensators was 381000 cycles $(\sigma \max =103,4 \mathrm{MPa}, \mathrm{R}=0,1)$. Klima [4] has obtained an increase in fatigue life from 235526 cycles (countersunk rivet, $100^{\circ}$ angle) to 471110 cycles (countersunk rivet with a compensator, $90^{\circ}$ angle). In this case, a different rivet head angle has affected fatigue life too.

The presented works were carried out under the Eureka project E3496! called IMPERJA. The goal of the IMPERJA project is to increase the fatigue life of riveted joints as well as to improve fatigue life estimation methods for such joints. This will lead to an increase in the aircraft service life, a smaller number of inspections and lower aircraft operating costs. The project included experimental and numerical analyses of stress and strain system around the rivet during and after the riveting process as well as the impact analysis of joint geometry and squeezing force. The investigation concerned sheets and rivets used in the Polish aerospace industry. This paper presents measurement results for two types of rivets; the normal brazier rivet (BN-70/1121-06) and the brazier rivet with a compensator (OST 1 34040-79 1) as well as the FEM analyses. The MSC MARC software was used. Geometry of rivets was presented in Fig. 1.

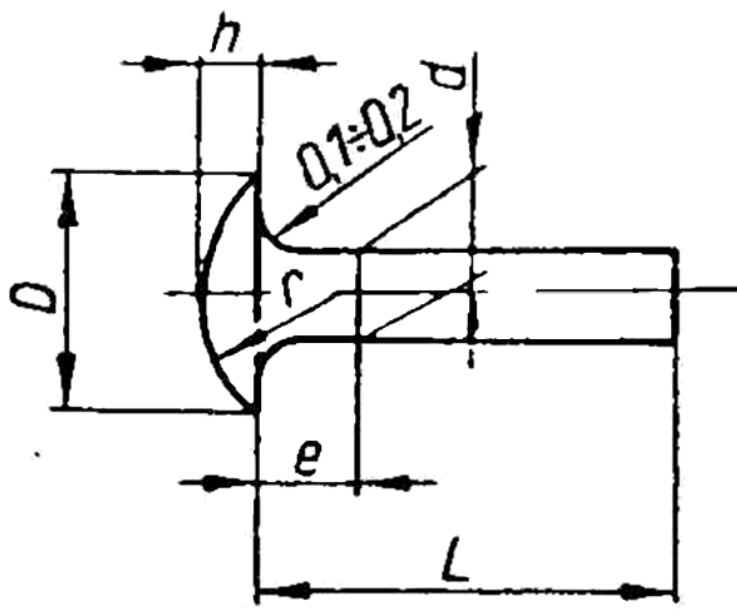

BNN-10/1121-06]

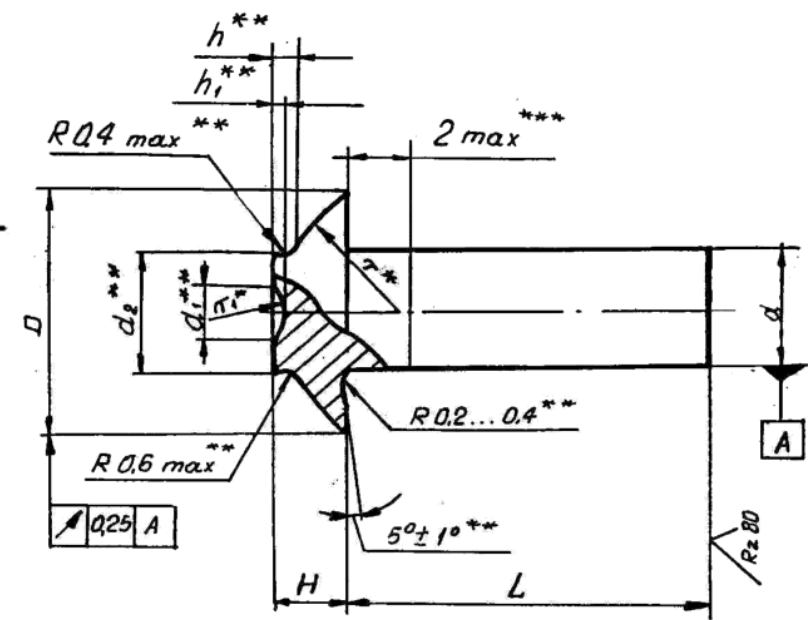

OST $134040-79$

Fig. 1. Geometry of analysed rivets 


\section{THE EFFECT OF SQUEEZING FORCE}

The WP6.1 series specimens were designed in order to investigate the squeezing force influence using the X-ray diffractometer. The geometry of specimens was presented in Fig. 2. Specimens were manufactured by the PZL Mielec.

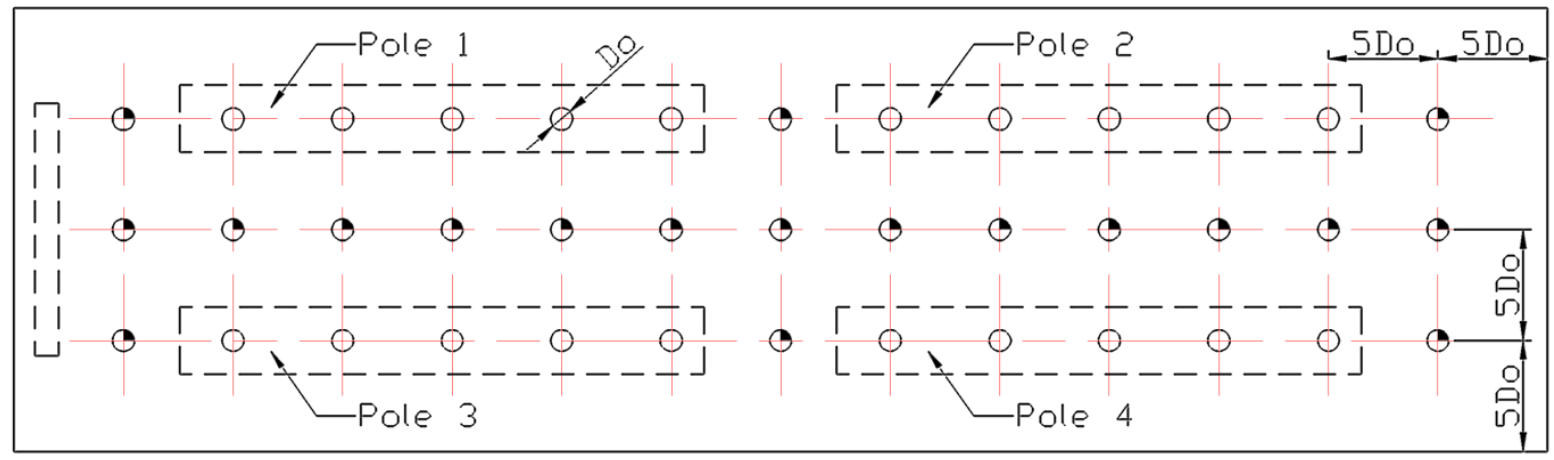

Fig. 2. WP6.1 specimens geometry

There are four fields on the specimen with five rivets in each field. The rivets inside the fields were installed on the testing machine with force control. The rivets in each field were upset with the same nominal force. The force values were attuned to obtain D/Do parameter (D-driven head diameter, Do-rivet shank diameter) equal to 1,$2 ; 1,4 ; 1,5$ and 1,55 respectively in the fields 1 to 4 . The paper presents results for the WP6.1.8.1 and WP6.1.9.1 specimens including 3-mm rivets according to the Polish aerospace standard BN-70/1121-06 (WP6.1.8.1) as well as the Russian aerospace standard OST 1 34040-79 1 (WP6.1.9.1).

Specimens consist of two bare sheets made of 2024-T3 alloy with a nominal thickness of 1,27 $\mathrm{mm}$. Rivets are made of the Polish aluminium alloy PA25. The distance between the rivets axes equals to 5 rivet diameter $(15 \mathrm{~mm})$.

\subsection{X-ray diffraction measurement}

In each field, one rivet (with dimensions of the driven head closest to the nominal values) was selected for radial and tangential stress measurements on the sheet surface, near the driven head. Measurements were carried out on the paths parallel and perpendicular to the rolling direction (the longest edge of the specimen). The first measurement point lies as close to the driven head as possible. The specimen with marked measurements paths was presented in Fig. 3.

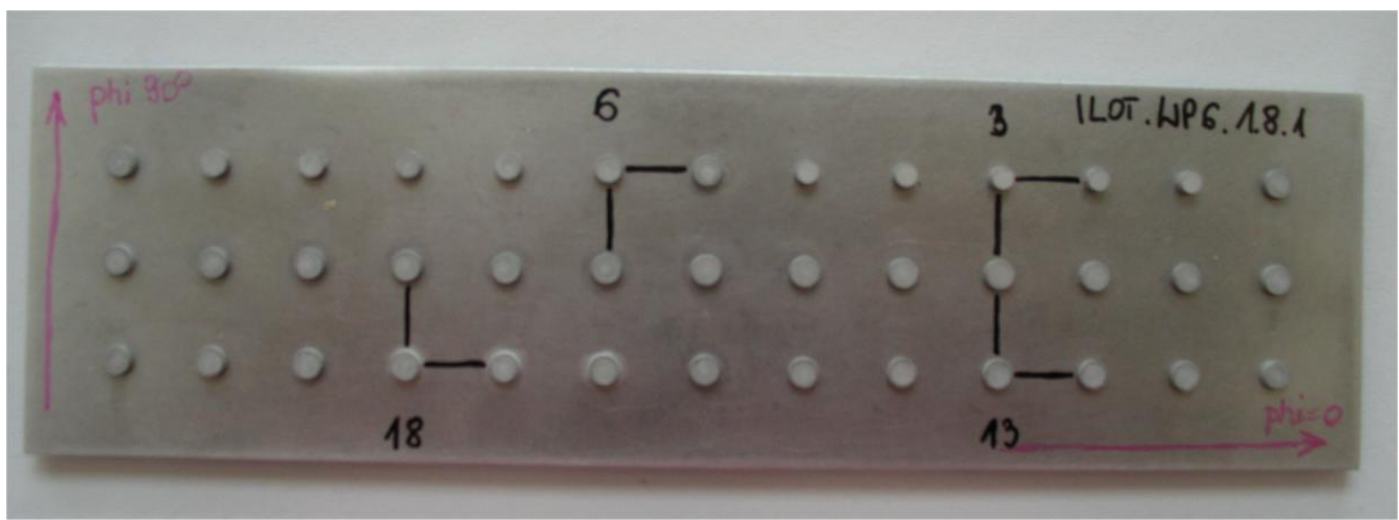

Fig. 3. WP6.1.8.1 specimen with numbered rivets and measurements paths 
Stress measurements were performed using the X-ray diffractometer XSTRESS3000, produced by Stresstech Oy. The device is presented in Fig. 4. Fig. 5. shows angels which define rotations of the diffractometer head.

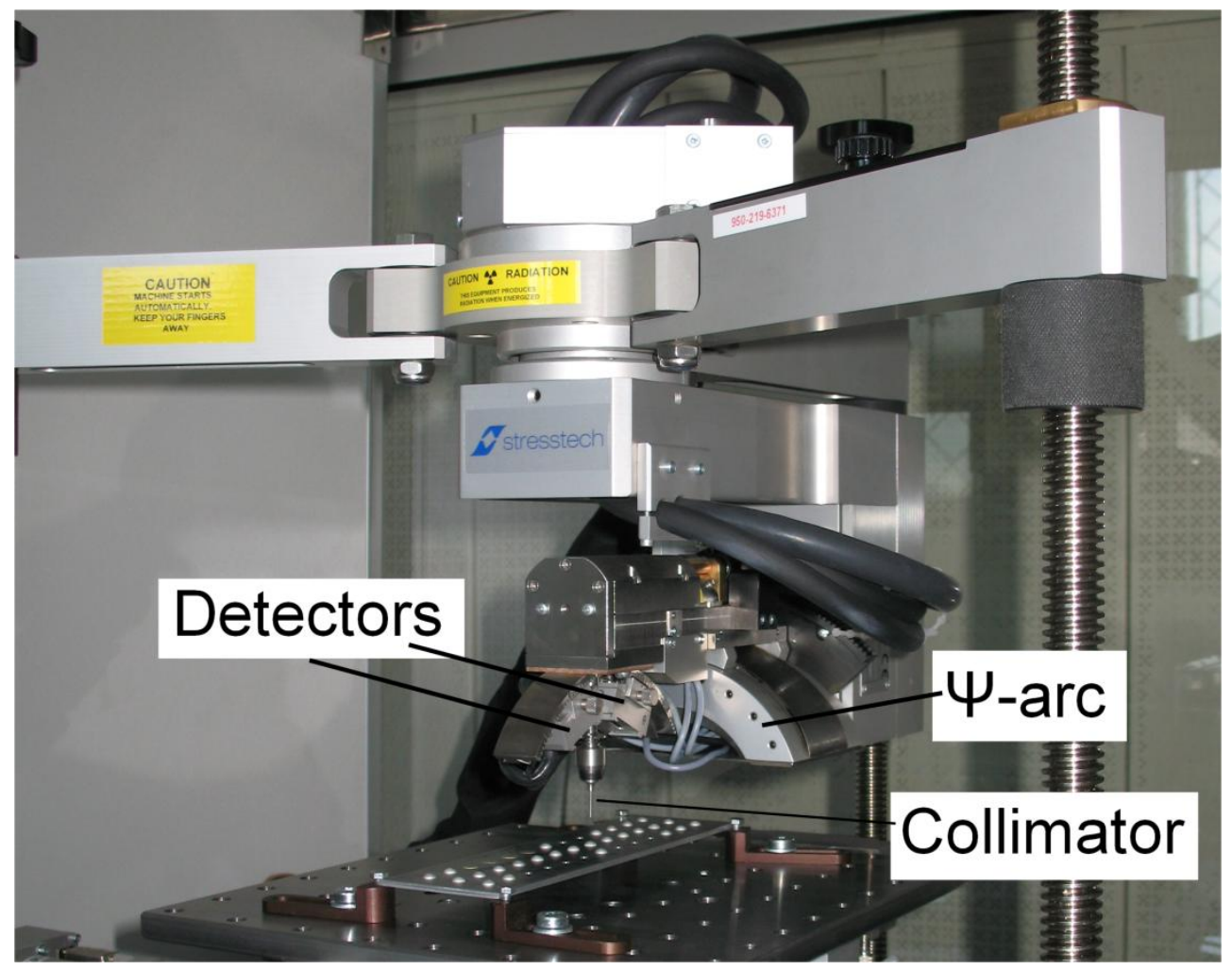

Fig. 4. XSTRESS3000 diffractometer
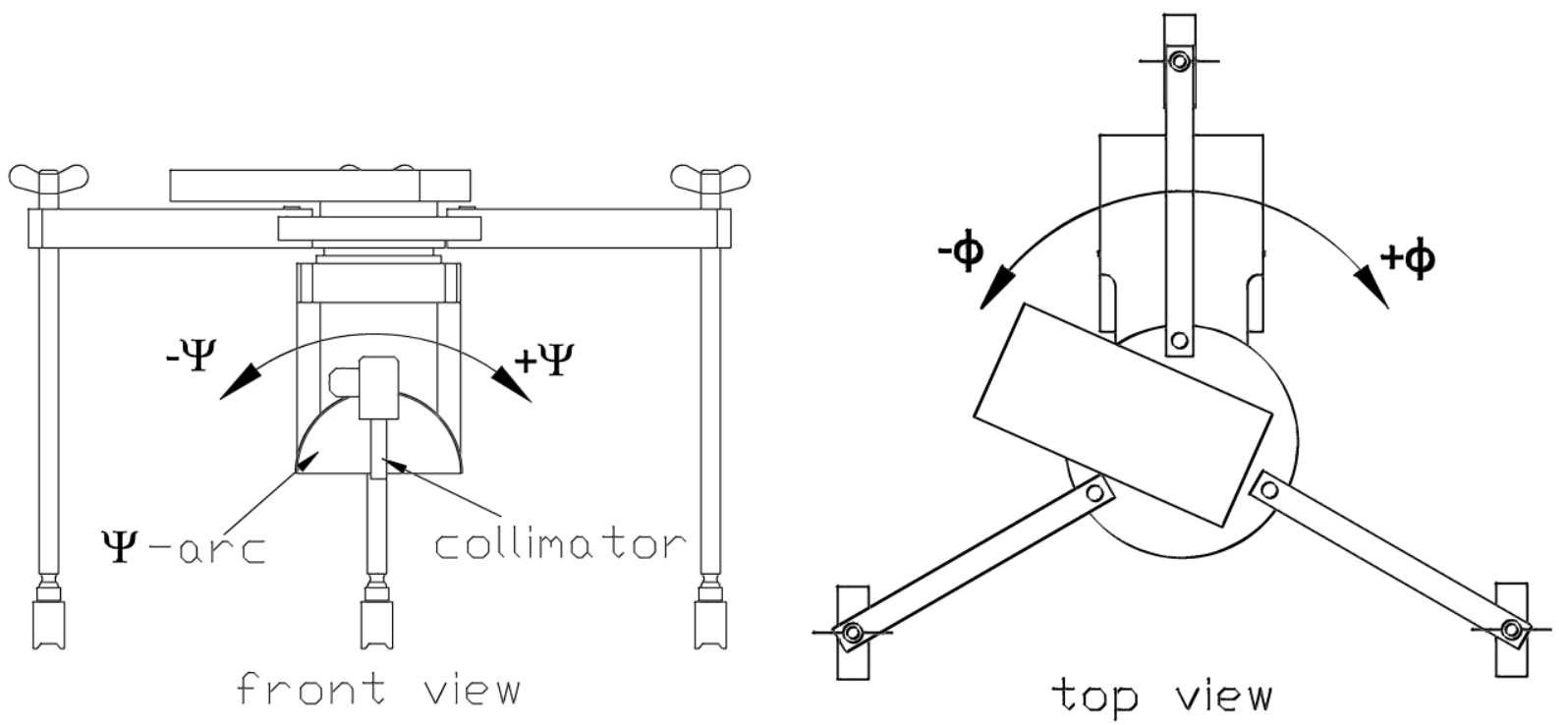

Fig. 5. Angles defining rotation of the diffractometer's head

During the X-ray diffractometry (XRD) measurements the X-ray beam falls through the collimator to the measurement point and the X-rays are reflected from the specimen. The detectors record reflected rays and the diffraction angle, for which positive interference of waves occurs, is determined. The determination of stress at one point in one direction requires such measurements 
for several rotations of the diffractometer's head including the collimator (several $\Psi$-angles - the angles between the X-ray beam before it is reflected and the normal to the specimen surface). The diffractometer's head rotates in the surface in which stress is determined. If the measurement point lies near the driven head, for some $\Psi$-angles the driven head could overshadow the measurement point or one of the detectors (Fig. 6).
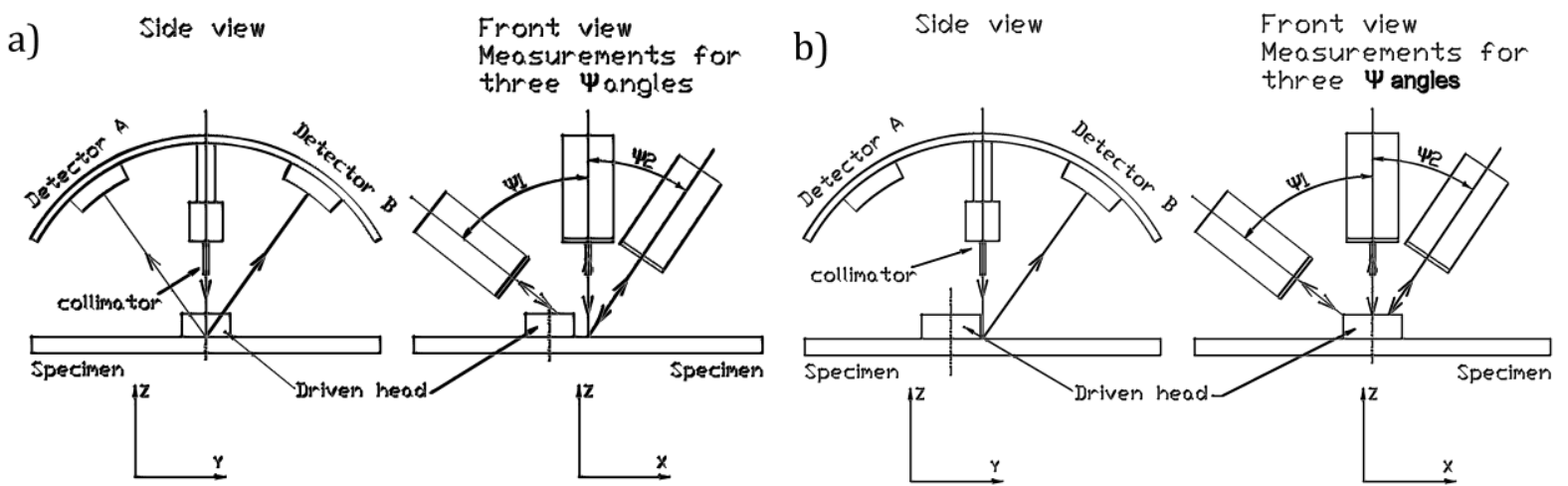

Fig. 6. Driven head shadow during measurements of stress a) radial, b) tangential

During the radial stress measurement (Fig. 6a, measurement point in front of the driven head in side view), for $\Psi 1$ angle the beam does not fall at the measurement point but at the driven head. In this case, $\Psi$ angle range was limited. During the tangential stress measurement (Fig. 6b, measurement point beside the driven head in side view) detector A is overshadowed for all $\Psi$ angles. For such points only one detector was used. The occurrence of the driven head shadow depends on the position of the measurement point as well as on the driven head dimensions. For all measurements, geometrical analysis was performed in order to eliminate the influence of the shadow.

Measurement parameters were collected in Table I. Material properties were assumed based on the research carried out at the University of Technology and Life Sciences of Bydgoszcz, Poland.

Table I. XRD measurements parameters

\begin{tabular}{|c|c|c|}
\hline Calculations: & $\begin{array}{l}\text { 2theta } \\
\text { Background subtraction } \\
\text { Detectors } \\
\text { Peak limits } \\
\text { Pick shift }\end{array}$ & $\begin{array}{l}\text { Calibrated } \\
\text { Linear } \\
\text { A i B } \\
\text { No } \\
\text { Cross correlation }\end{array}$ \\
\hline $\begin{array}{l}\text { Collimator- } \\
\text { specimen distance: }\end{array}$ & d & $4.46 \mathrm{~mm}$ \\
\hline Material data: & $\begin{array}{l}\text { Material } \\
\text { Young's modulus E } \\
\text { Absorption coefficient } \mu \\
\text { Poisson's ratio } \nu\end{array}$ & $\begin{array}{l}\mathrm{Al}(156,7) \\
70600 \mathrm{MPa} \\
42.71 / \mathrm{mm} \\
0.345 \\
\end{array}$ \\
\hline $\begin{array}{l}\text { Measurement } \\
\text { parameters: }\end{array}$ & $\begin{array}{l}2 \Theta / h k l \\
\text { Exposure time } \\
\text { Method } \\
\Phi \text { values } \\
\Phi \text { oscillation } \\
\Psi \text { values } \\
\Psi \text { oscillation, angle and } \\
\text { number } \\
\text { Tube } \\
\end{array}$ & $\begin{array}{l}156.7^{\circ} / 311 \\
\max 120 \mathrm{~s} \\
\text { (various) } \\
\mathrm{Psi} \\
0 ; 90 \\
10^{\circ} / 5 \\
-39^{\circ} /+39^{\circ} \\
\pm 6^{\circ} ; 5 / 5 \\
\mathrm{CrKa} \\
\end{array}$ \\
\hline Collimator: & diameter & $0,8 \mathrm{~mm}$ \\
\hline
\end{tabular}


The results of the measurements were collected in Table II. Graphs for the specimen WP6.1.8.1 (brazier rivet BN-70/1121-06) are in the left column, for the specimen WP6.1,9.1 (rivet with a compensator OST $134040-79$ 1) in the right column. The name of the series indicates the rivet number and the measurement path (l-lengthwise to the rolling direction, w-crosswise to it). For particular rivets, the value of D/Do parameter (D-driven head diameter, Do-rivet shank diameter) is equal to 1,2 (rivet no 3 and 4), 1,4 (no 6 and 8), 1,5 (no 13 and 14) and 1,55 (no 17 and 18).

Table II. Results of XRD measurements

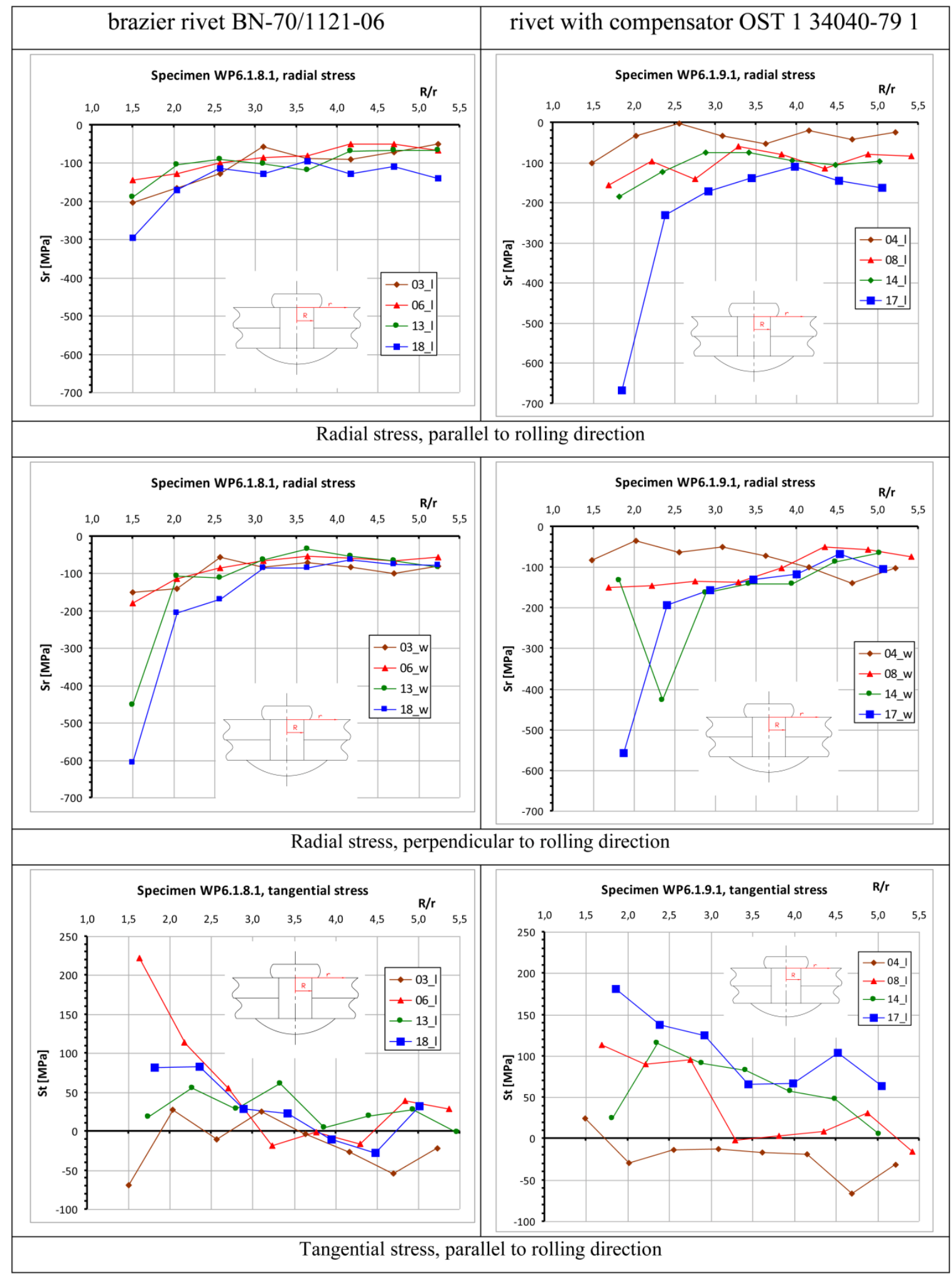




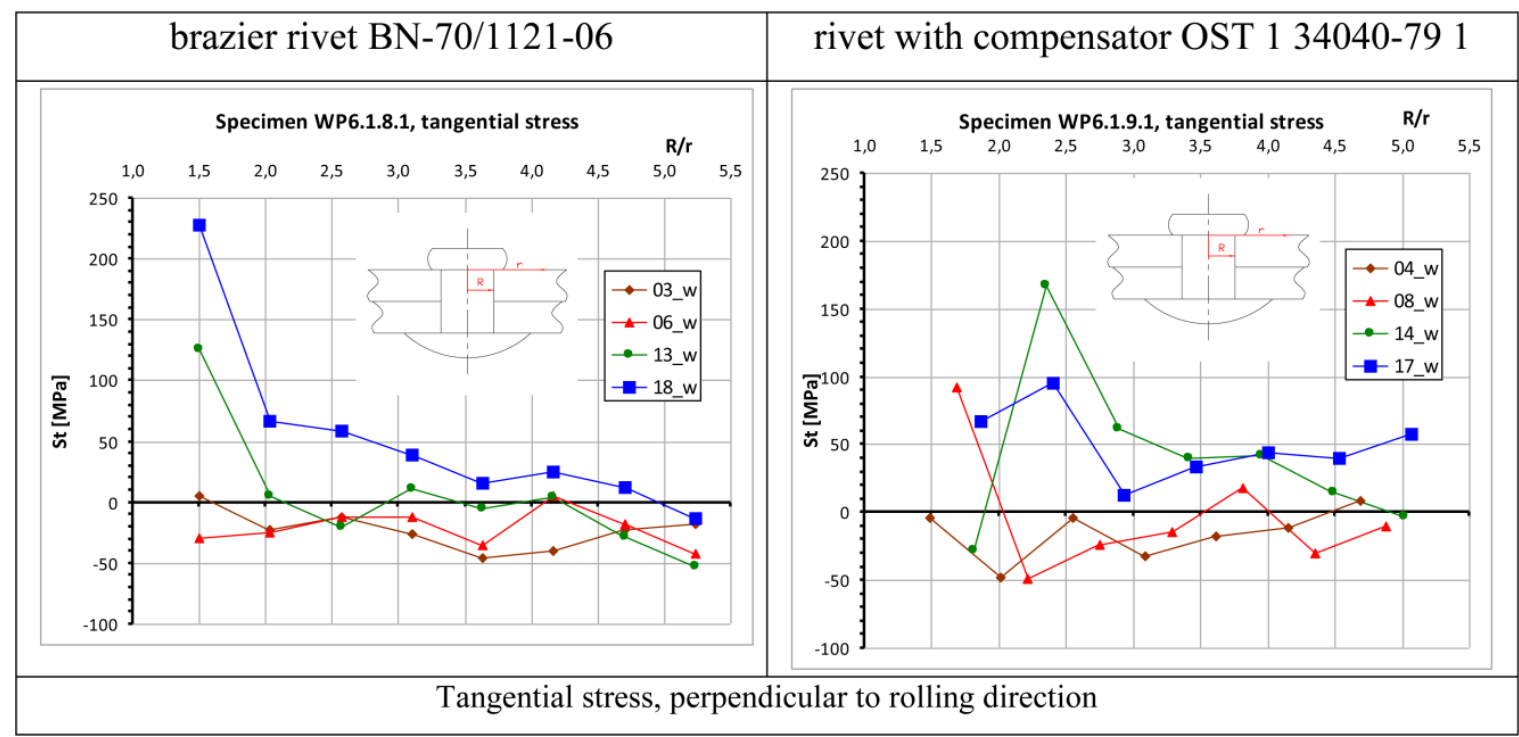

The graphs of radial stresses agree with literature. In tangential stress graphs, disturbances are present. The effect of the squeezing force value can be seen in both types of stress plots.

There are differences between the results of the measurements on paths lengthwise and crosswise to the rolling direction. The curves in the graphs are not smooth in many cases. Probably it is a result of residual stresses, which were present in the sheets before the riveting process (after rolling, drilling etc.). Moreover, the measurement point nearest to the driven head are in the area where stress exceeded the yield point during riveting. The method of stress determination used in the presented measurements concerns the elastic range only. Besides, in this area driven head overshadowing occurs, which limited measurement capability. This causes that the results of the measurements in the immediate vicinity of the driven head are less reliable. 


\subsection{FEM calculation}

Axisymmetric FEM models were prepared for analyses of stress system around the rivets. The models refer to the specimens on which XRD measurements were carried out. Each of the model consists of five contact bodies; three deformable ones (two sheets and a rivet) and two rigid ones that simulate effect of the hold-on and the press punch. The dimension of the models was restricted to 5 rivet radius (half distance between rivet axes on WP6.1 specimens). Each of the model consists of about 2000 linear elements and nodes in the model of the rivet with a compensator, the local adaptivity function (local splitting of elements) was activated near the compensator due to high strain in this area. The models are presented in Fig. 7.
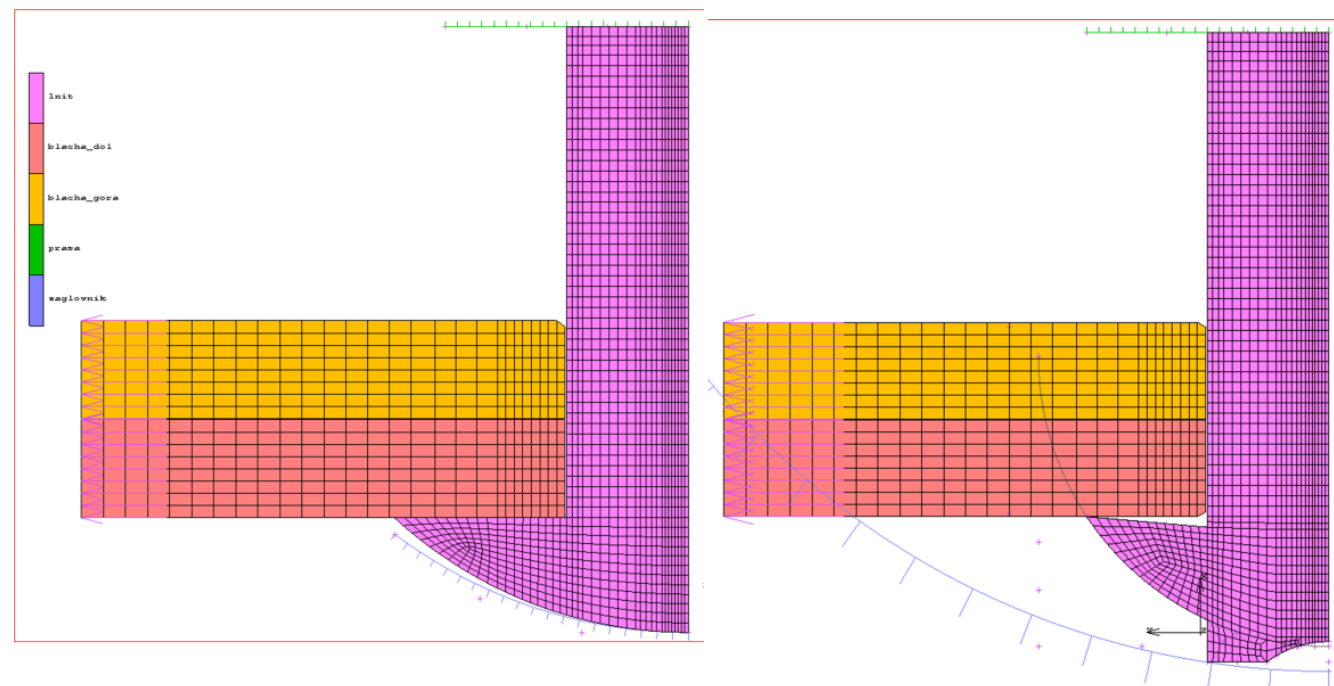

Fig. 7. FEM models

The models of the materials, developed based on monotonic tests of specimens cut from sheet (2024-T3) and rivets (PA25), were used. The tests were carried out by Prof. Małgorzata Skorupa's team at the AGH University of Science and Technology in Cracow. The material models are presented in Fig. 8.

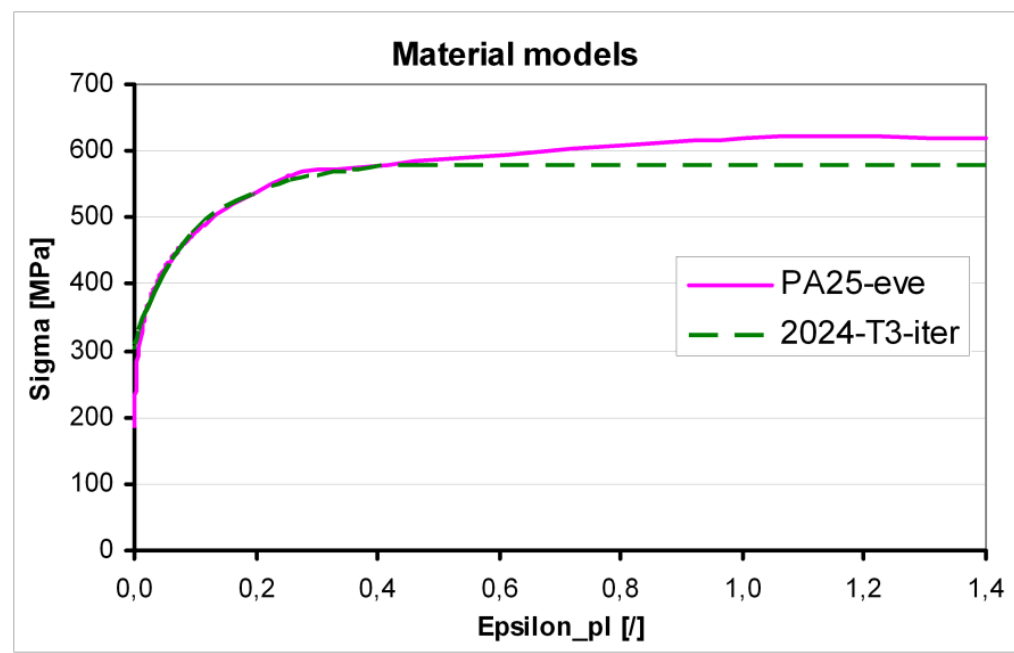

Fig. 8. Material models

A stick-slip Coulomb model of friction was selected. For sheets and sheet-rivet contact pairs, the dynamic friction coefficient equal to 0,34 was assumed [5]. For contact between the rivet and rigid bodies, the friction coefficient value was 0,15 . Static friction coefficients were $24 \%$ higher. 


\section{Boundary conditions}

Boundary conditions are presented in Fig. 9a.

During the whole analysis the hold-on did not move. The press punch was able to move only in the axis direction ( $\mathrm{x}$ ) and was controlled by force equal to $10,4 \mathrm{kN}$ (brazier rivet) and $12 \mathrm{kN}$ (rivet with a compensator).

Nodes on the rivet axis could not move in the radial direction.

The same condition was applied to the nodes of the sheets on the outer edge of the model (reaction of not modelled part of the sheets).

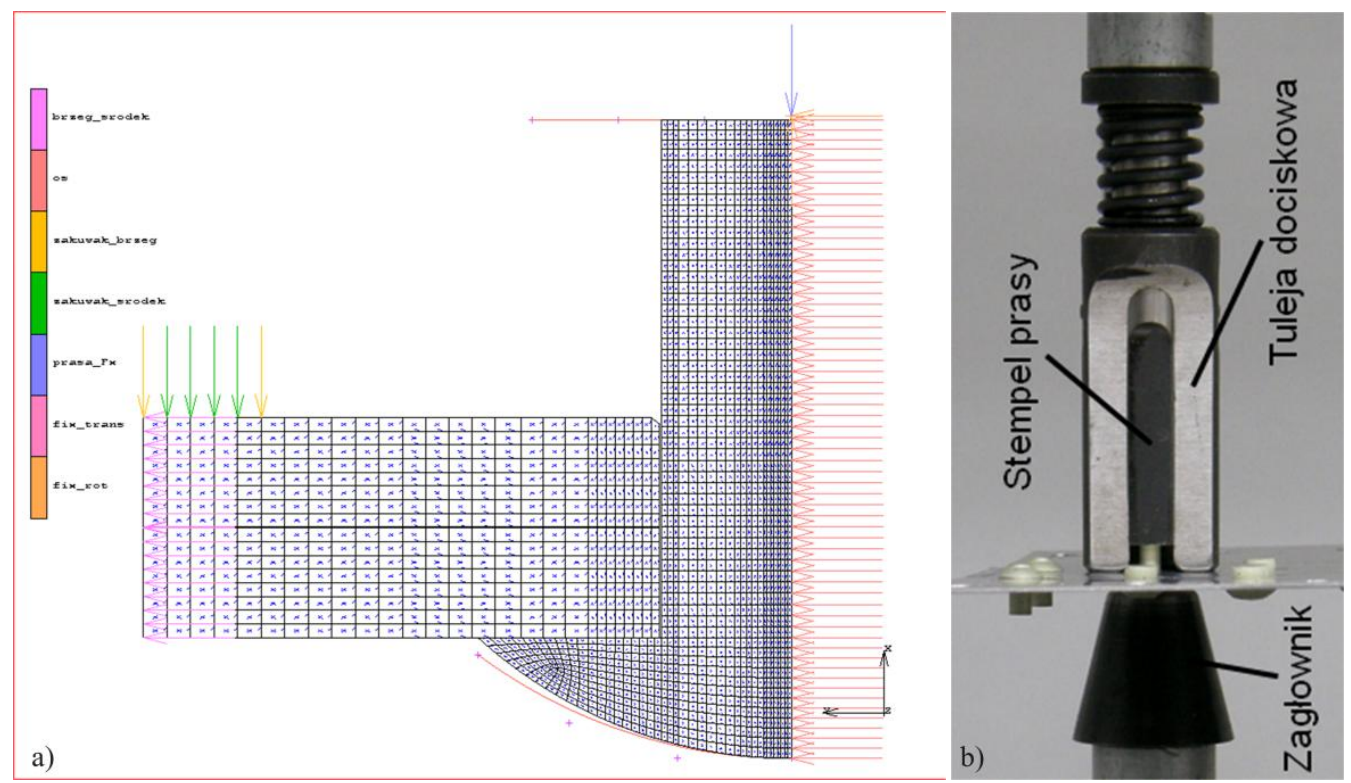

Fig. 9. Boundary conditions, a) FEM model, b) real specimen

Riveting on the press is performed with the riveting set (Fig. 9b) consisting of the punch and the clamping sleeve. During the riveting process, before the punch touches the rivet shank, plates are pushed together by the sleeve, which is coupled with the punch by a spring. To take this into account during FEM analysis, the forces equal to the one acting on the sleeve were applied to the nodes belonging to the surface on the upper (inner) sheet (Fig. 9a). The value of the force was estimated based on the stiffness of the spring and sizes of the driven head and the riveting set. The assumed course of the forces applied to the sleeve and the punch during the riveting process in shown in Fig. 10.

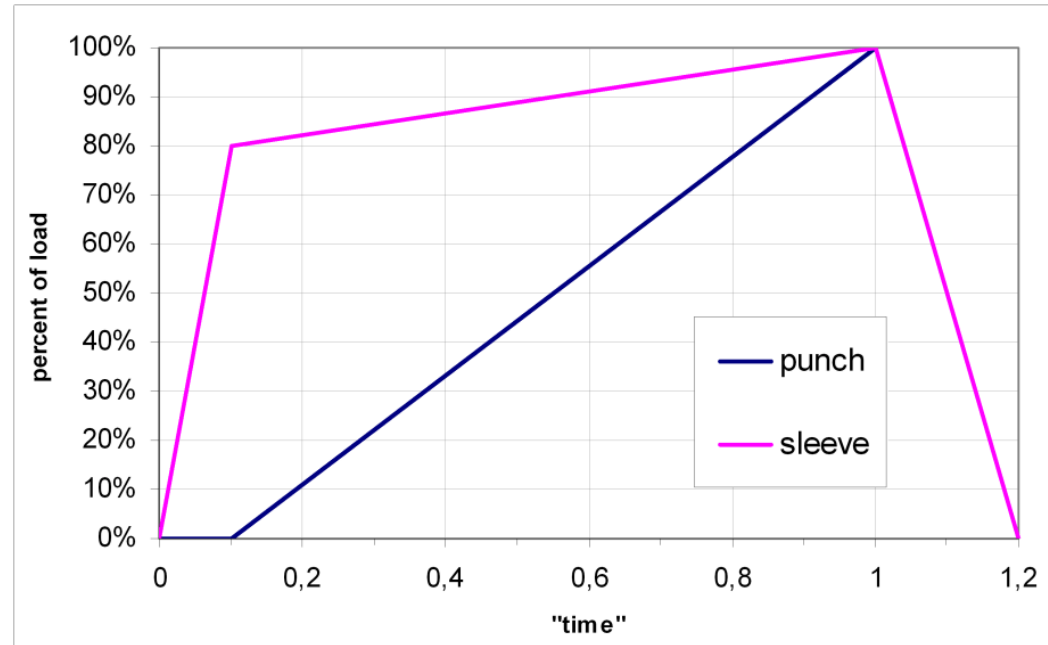

Fig. 10. Course of the forces applied to the sleeve and the punch during analysis 1-maximum force, 1,2-release 


\section{Results}

Numerical calculations were compared with XRD measurements. In the graphs, the results were compared directly. This way of comparing FEM results and neutron diffraction measurements was employed in [6]. It should be noted that the X-ray (neutron) diffractometer measures total stress, which comprises stresses induced during riveting process as well as residual stresses after rolling, heat treatment, drilling etc, which makes the comparison more difficult. The authors intend to measure the residual stresses existing in the sheets before riveting and to develop a method of using this information for validation and verification of the FEM models.

The numerical results show quite good agreement with measurements. In the case of radial stresses around the brazier rivet, the values (absolute) from the FEM calculation are higher than those obtained in the measurements. The biggest difference exists near the rivet hole in the plastic zone where the measurements are less reliable. In the graphs, the equivalent stresses are presented and the plastic zone radius is determined. Graphs were presented in Table III.

Table III. Comparison of FEM calculation and XRD measurements

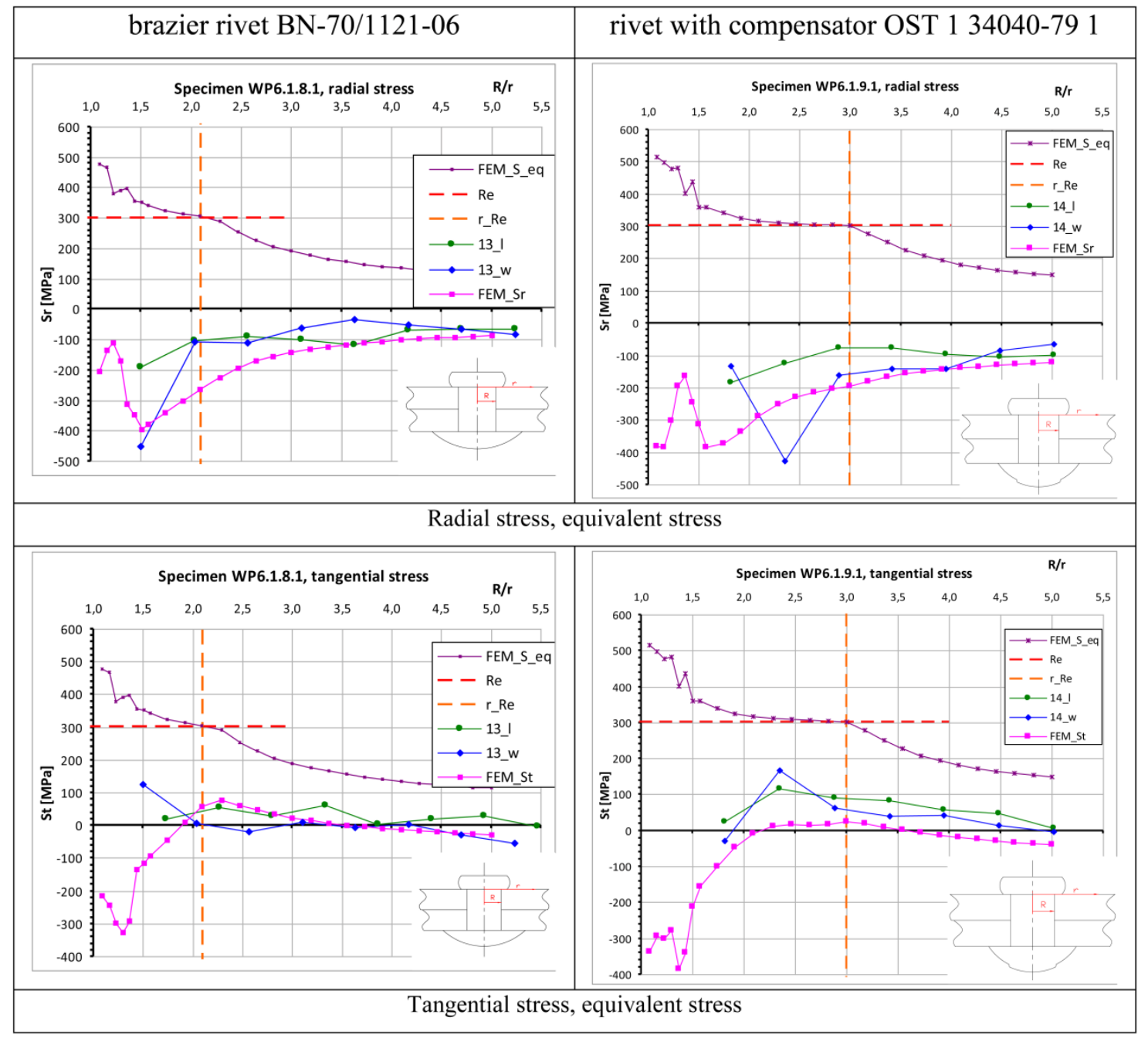

The courses of squeezing force as a function of punch displacements obtained in calculation were compared with the experimental data. The displacements in the FEM analyses were slightly lower than those recorded during the test. The flexibility of the riveting system was determined and the experimental data were corrected. After this operation, the correlation between the calculation and the experiment was better, but still displacements obtained in the numerical 
analyses were somewhat lower than in reality. Fig. 11 presents squeezing force as a function of punch displacement for the calculations and experiments.

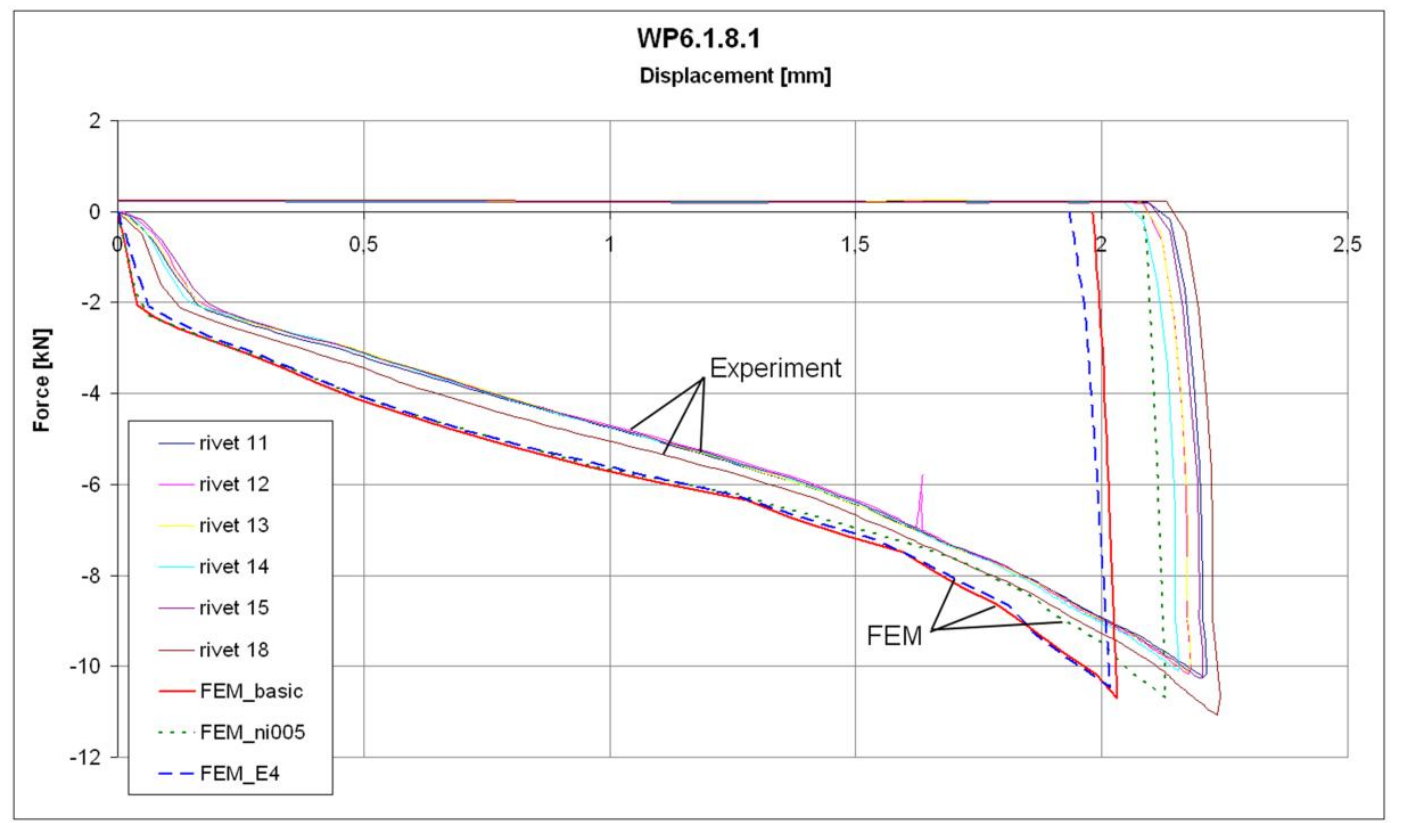

Fig. 11. Squeezing force as a function of punch displacement during riveting process

Additional calculations were performed. The continuous line represents the basic model, the dot line the model with the friction coefficient between the sheets and rivets limited to 0,05 . In the initial elastic phase of the riveting process (squeezing force below $2 \mathrm{kN}$ ), the slope (stiffness) of numerical curves is higher than that of experimental ones. The calculation with Young modulus reduced to $40 \mathrm{GPa}$ was performed (dash line). This change did not affect significantly the curve course.

There are differences between the curves obtained during the calculation and experiment, which indicates that the models should by refined. Nevertheless, the character and values of the curves are similar. Moreover, good correlation between calculation and XRD stress measurements have been obtained. The models were used to study the effect of the squeezing force.

The calculations were performed with the models of two types of brazier rivets, normal and with a compensator, with squeezing force values recorded in the experiments. The results were collected in Table IV. The graphs present stresses on the surface near the driven head. The series name indicates the squeezing force value. The graphs correspond to the graphs from Table II.

Table IV. Results of FEM calculations with various squeezing force-stresses on the sheet surface on the driven head side

brazier rivet $\mathrm{BN}-70 / 1121-06 \quad$ rivet with compensator OST $134040-791$




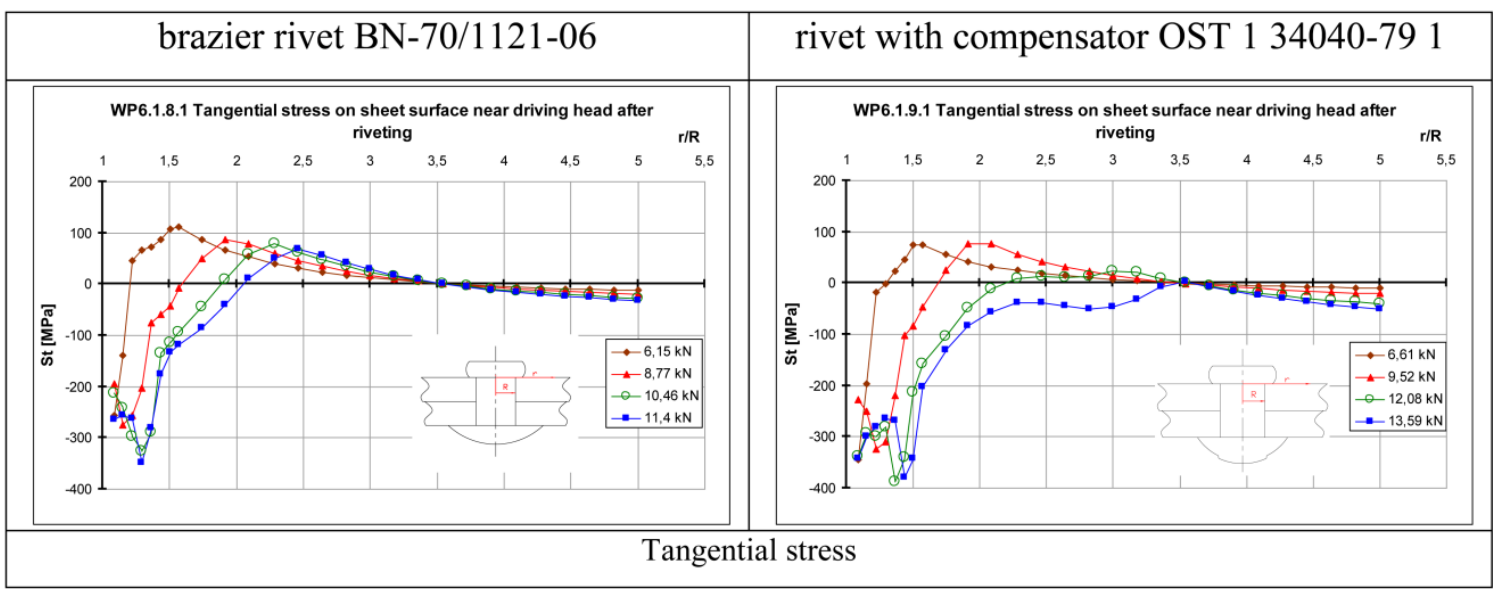

The squeezing force effect is clearly visible. For higher forces, radial compressive stresses are higher and the local extremes are farther from the rivet. This shift in the position of the curve is stronger for the rivet with a compensator, but, in this case, the force increase was bigger. A similar effect occurs in the case of tangential stresses. The increase in squeezing force results in a shift of the stress curve in the direction of higher compression and higher values of the $\mathrm{r} / \mathrm{R}$ parameter (farther form the rivet). The local maxima of tension stresses are lower and located farther from the rivet, especially for the rivet with a compensator, where compressive stresses are present virtually in the entire area around the rivet for the highest force.

The squeezing force effect was recorded in the XRD measurements (see Table II), but it is not as strong as in numerical calculations. This might be partly due to presence of residual stresses in the specimens. It is possible, however, that the FEM models do not reflect all essential phenomena of the riveting process. Moreover, the XRD measurement methodology is still being developed and verified.

The presence of compressive stresses is beneficial from the fatigue point of view, especially on the faying surface, which is where fatigue cracks largely appear. Stresses as functions of distance from the rivet axis are presented for both sheets in Table $\mathrm{V}$.

Table V. Results of FEM calculations with various squeezing forces - stresses on the faying surface

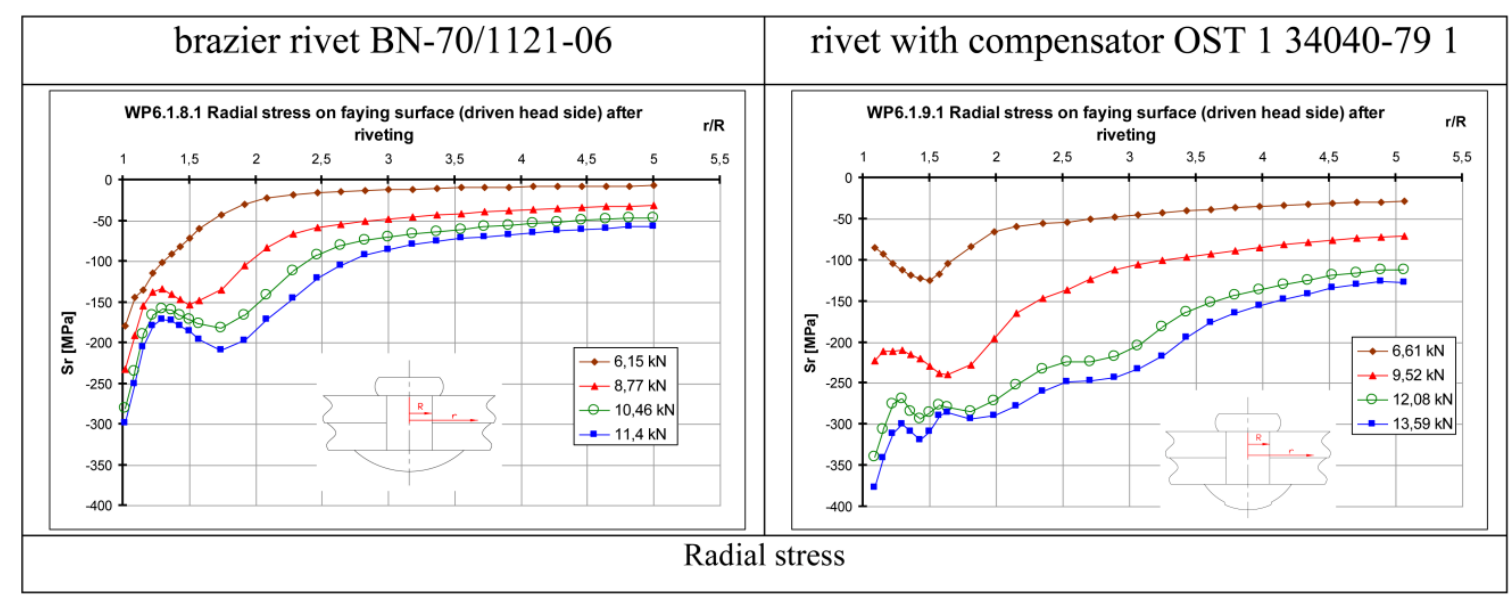




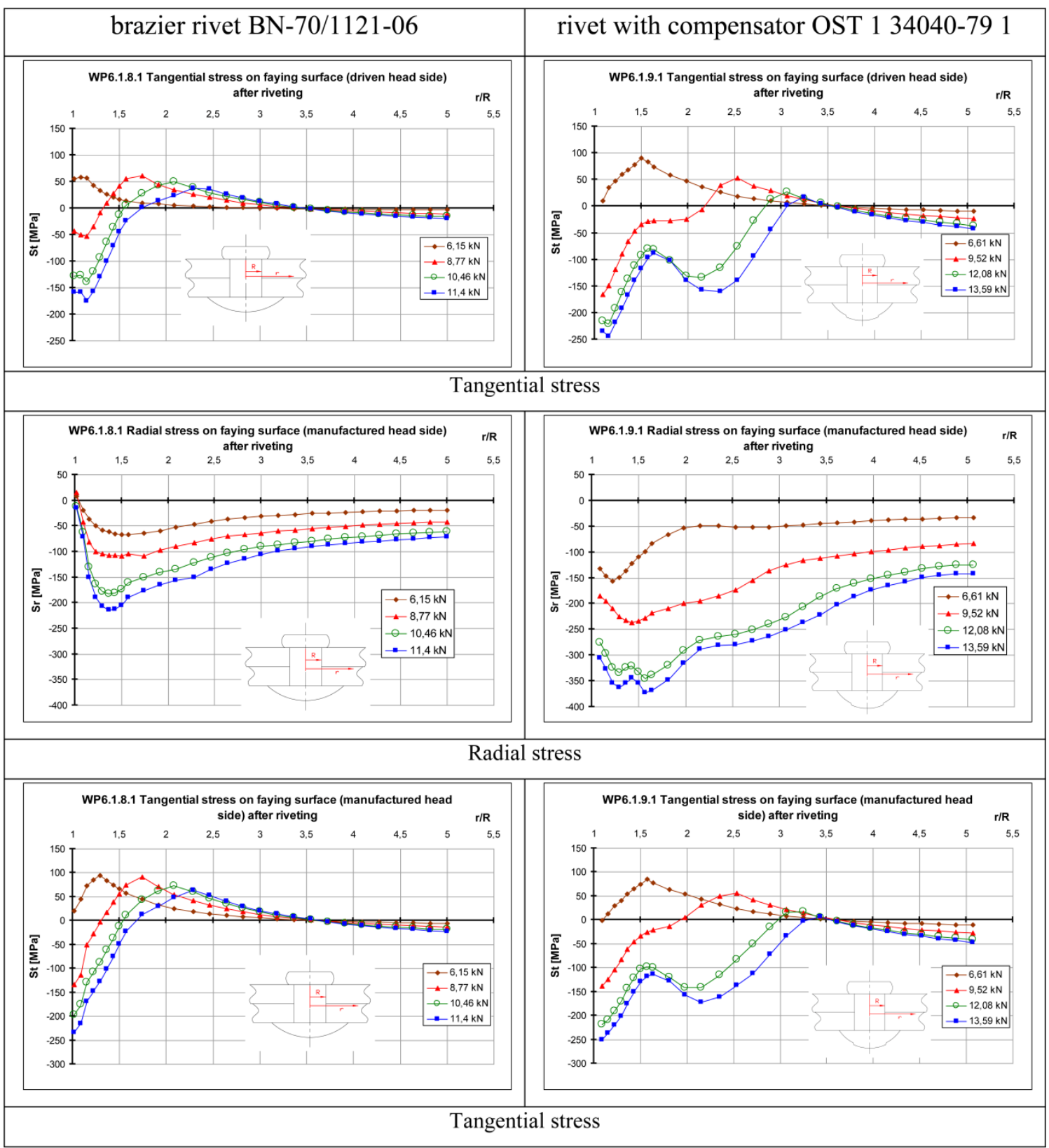

The squeezing force effect on the faying surface is similar to the effect on the sheet surface near the driven head. For the lowest squeezing force, tension residual tangential stresses occur in the area near the rivet for both types of the rivets. For the highest squeezing force, for the rivet with a compensator, compressive stresses are present almost across the whole $\mathrm{r} / \mathrm{R}$ range. The are local extremes in the graphs of radial stresses (brazier rivet) and tangential stresses (rivet with a compensator) for medium and high squeezing force values. The characters of the graphs are different for low squeezing forces. This is probably connected with the low level of plastic strains on the faying surface.

\section{STRAIN PROGRESS DURING RIVETING PROCESS}

The literature and FEM calculations indicate the existence of high stress and strain gradients near the rivet hole. The XRD measurements covered a region on the boundary or outside the high gradient stress area. To measure strain in the area of high stress and strain gradients, the WP6.2 
series specimens were designed and manufactured. Strain progress was recorded during the riveting process.

The geometry of the specimens is presented in Fig. 12. The specimens consist of two bare sheets made from 2024T3 aluminium alloy with a nominal thickness of 1,27 mm and three rivets with a diameter of $3,5 \mathrm{~mm}$ made from the Polish aluminium alloy PA25. The rivet types used in the WP6.1 specimens for XRD measurements were selected; BN-70/1121-06 (specimen WP6.2.8.1) and OST $134040-79$ (WP6.2.9.1). Strains were measured on the sheet surface near the driven head.

\subsection{Experiment}

After the outer rivets were installed, the strain gauges were applied, then the central rivet was installed and strain progress was recorded. The strain gauges should have very small gauge length and should be placed as close to the rivet hole as possible due to the high strain gradient. Two types of gauges were used: strip and micro gauges. The Vishay EA-13-XXXXX-120 strain gauges were employed (XXXXX stands for a gauge type). Strip miniature gauges contain ten gauges, each with a gauge length of $0,51 \mathrm{~mm}$, and were located outside the driven head. They worked during the whole riveting process. The 020MT gauges measured radial strain, while the 020PF gauges measured tangential strain. Additionally, two micro strain gauges with a gauge length of $0,38 \mathrm{~mm}$ were applied very close to the rivet hole, in the area which is under the driven head after the riveting process. The gauges recorded strains until they were destroyed by the driven head. The 015CK gauges measured radial strains, while the 015SE gauges measured tangential strains. The placement of the gauges and their numbering are presented in Fig. 12, radial positions of the gauge centre are in Table VI. In the case of strip gauges, only the positions of the first sections are shown. The distance between the sections is $0,89 \mathrm{~mm}$.

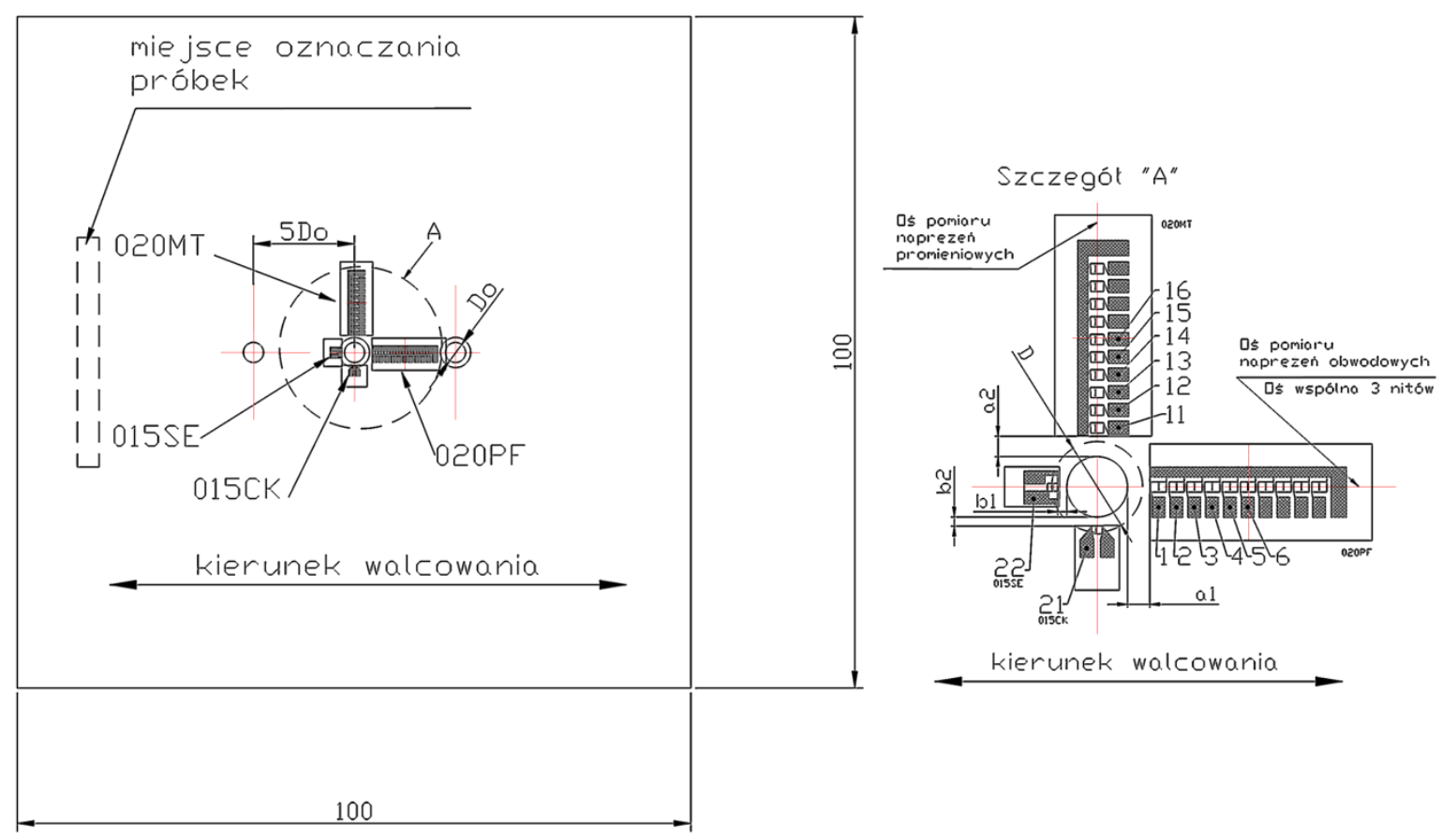

Fig. 12. WP6.2 specimens geometry

Table VI Radial position of strain gauges [mm]

\begin{tabular}{|c|c|c|c|c|}
\hline specimen $\mid$ gauge & $015 \mathrm{CK}$ & $015 \mathrm{SE}$ & $020 \mathrm{MT}$ & $020 \mathrm{PF}$ \\
\hline WP6.2.8.1 & 1,90 & 1,97 & 3,67 & 3,74 \\
\hline WP6.2.9.1 & 2,15 & 1,95 & 3,58 & 3,91 \\
\hline
\end{tabular}


Riveting of the central rivets was performed in the Institute of Aviation with the MTS 312/68 testing machine. When the standard riveting set (Fig. 13a) is used, before the punch touches the rivet shank, the plates are pushed together by the sleeve. To avoid damaging gauges by the riveting set, a special device was designed and manufactured (Fig. 13b). The sleeve was replaced with the special four-legged part. The legs press the sheets within a much larger radius than the standard sleeve does. To avoid specimens' bending, the support in the form of a ring with an inner radius of $80 \mathrm{~mm}$ and width of $10 \mathrm{~mm}$ was introduced. The ring is located under the legs and is connected with the testing machine by a spring, so it is able to move slightly in the axis direction within an adjustable range.

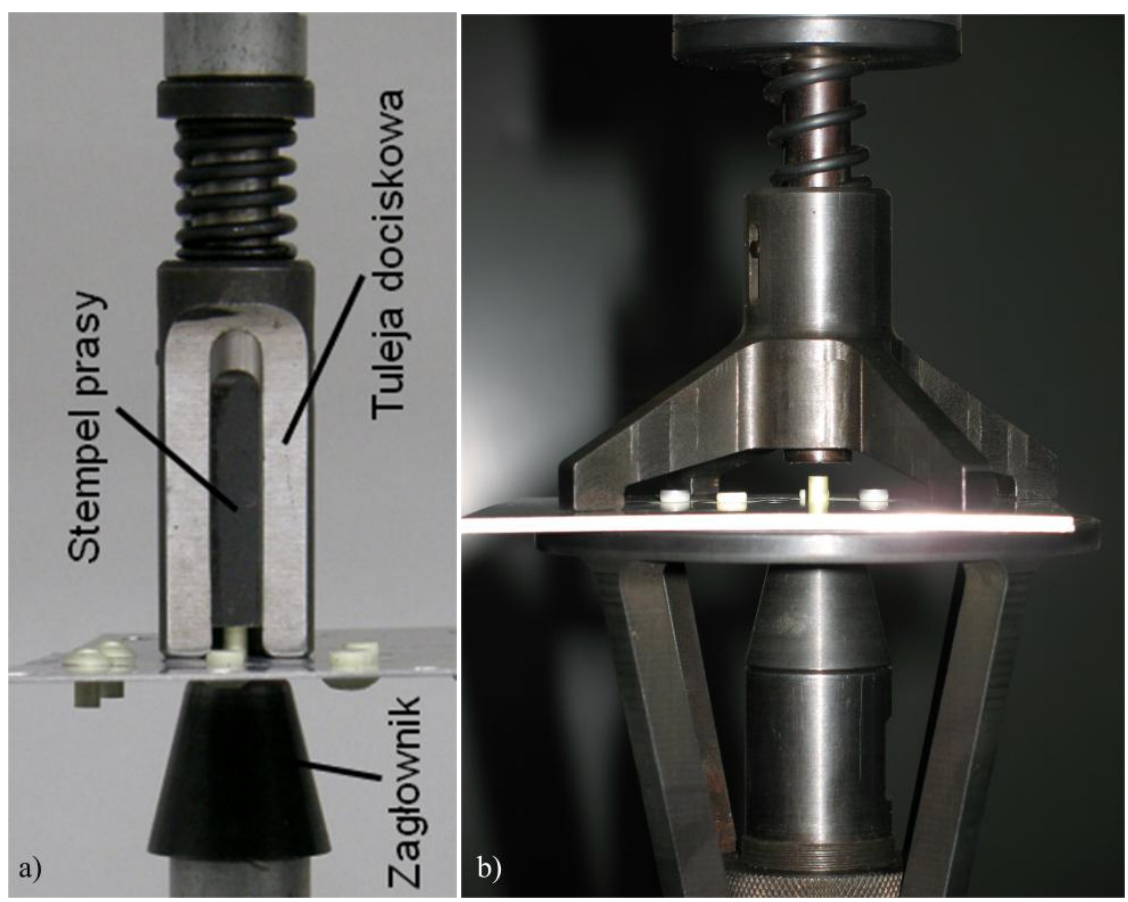

Fig. 13. Riveting set, a)standard, b) designer for WP6.2 specimens 


\subsection{Results}

The recorded strains were collected in Table VII. The graphs present strains in particular gauges as a function of squeezing force. Because of malfunction of one testing card strains of gauges no 3 were not recorded.

Table VII. Strains in particular gauges

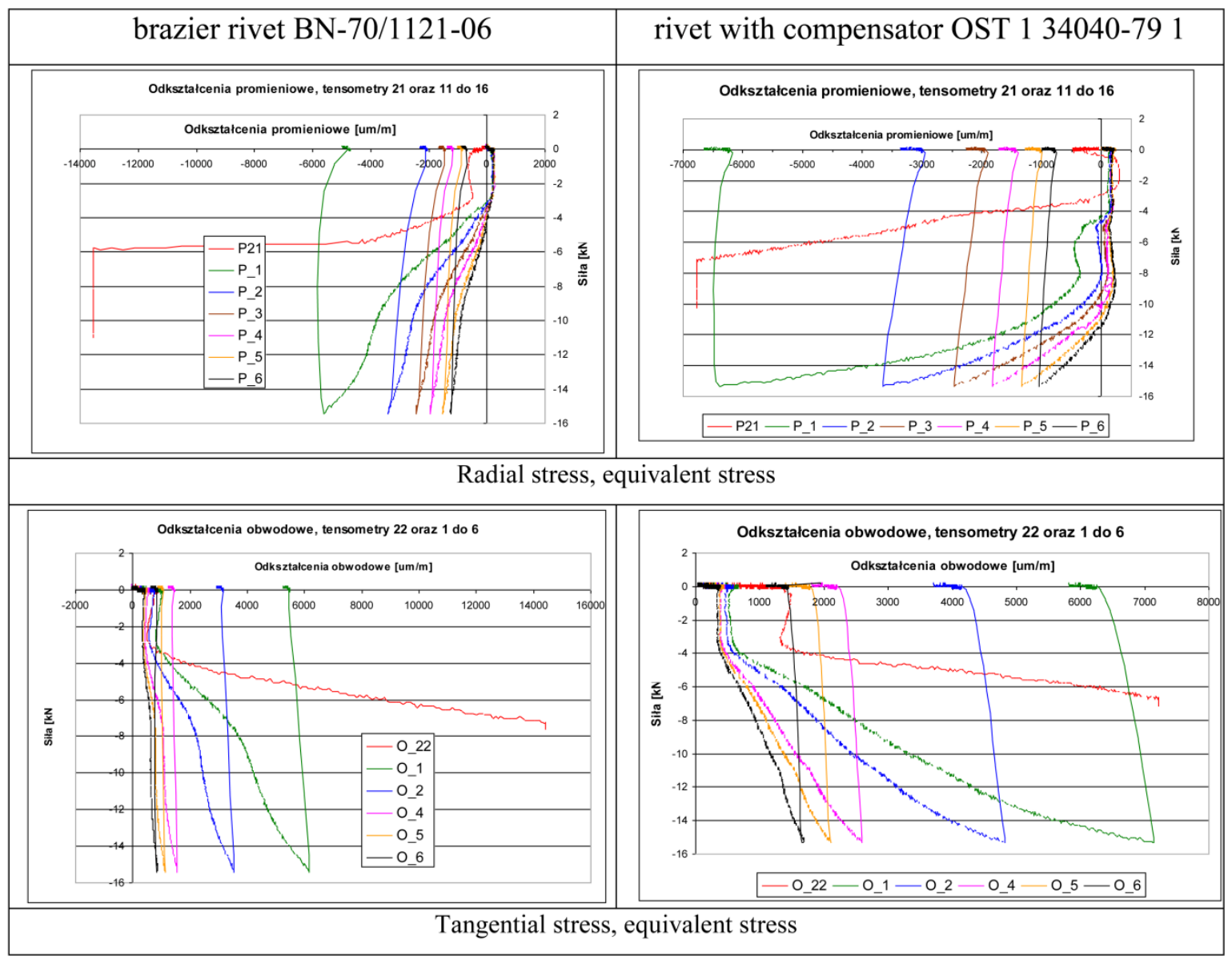

The "S" shaped curve can be seen in the radial strain graph for the rivet with a compensator. Similar shapes of strain plots were presented in paper [7] and [8]. This phenomenon has not been explained so far. The micro gauges placed nearest the rivet hole recorded considerably larger strains near the brazier rivets. At the same time, the strains recorded by gauges no 1 and 11 were somewhat higher near the rivet with a compensator.

Table VIII presents strains as a function of distance from the rivet axis. Each graph shows results for both rivet types. A series name indicates the type of the rivet (BN-brazier rivetcontinuous line, OST-rivet with a compensator-dashed line) and squeezing force for a particular plot. The strains recorded just before damage of the micro gauges and for the maximum force are presented in the first row. It should be noted that each micro gauge was damaged with a different force so it is impossible to compare directly plots for both rivet types. The graphs of strains for the maximum force and for release (end of the process) are in the second row. 
Table VIII. Strains as a function of radial position

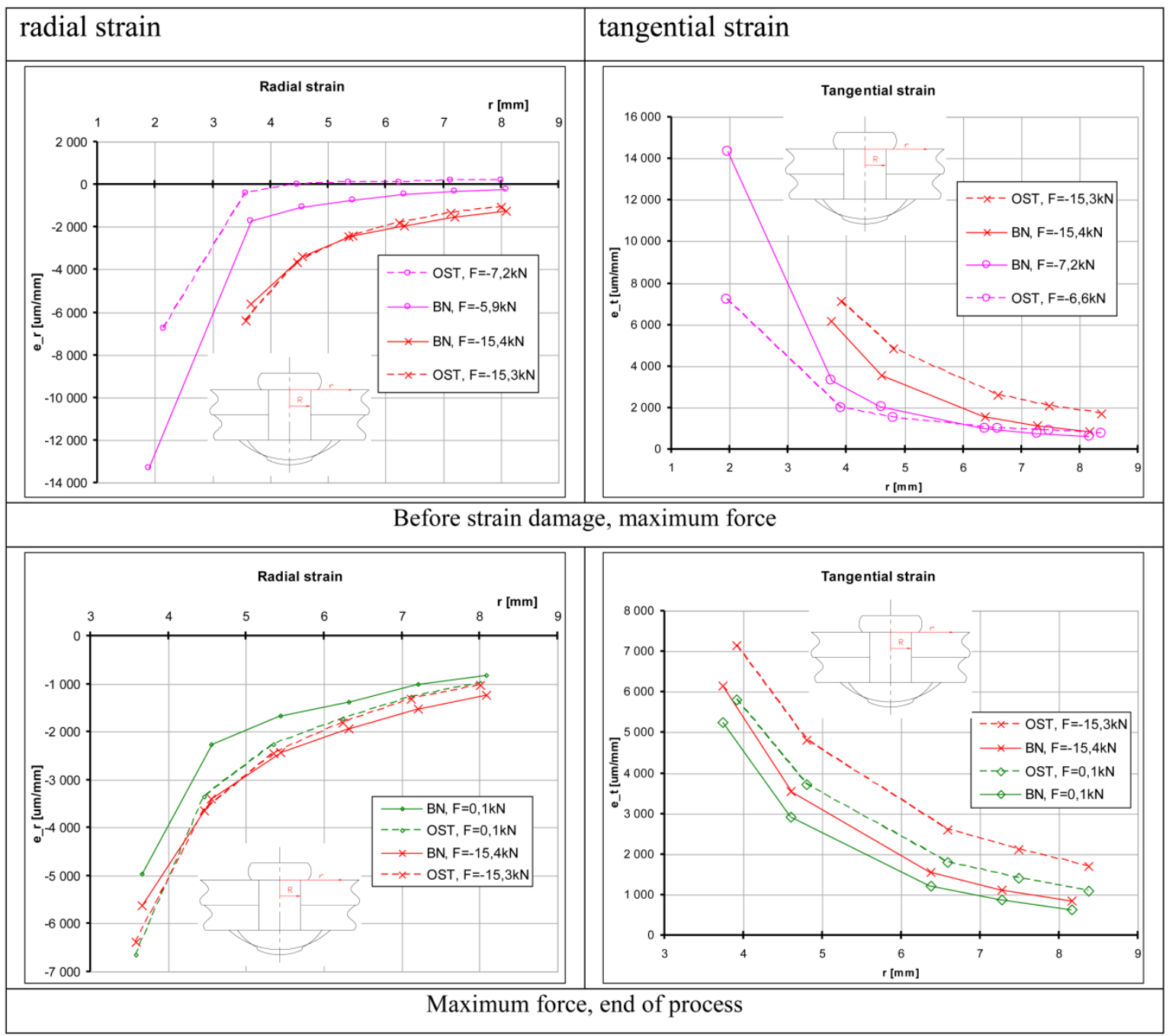

Gauge no 11 (radial strain) was damaged with a lower force in the specimen with a brazier rivet than it was in the other specimen (first row). Despite this, the strain recorded by this gauge is much higher than the one recorded near the rivet with a compensator. This indicates a faster strain progress in the case of the brazier rivet. Also tangential strain for this rivet is higher, but it was recorded with a higher force.

In the graphs in the second row, one can see that for the maximum force radial strains were higher near the brazier rivet, while after the riveting process radial strains were higher near the rivet with a compensator. Strain relaxation was significantly higher near the brazier rivets. Tangential strains were higher around the rivet with a compensator for the maximum force as well as after riveting. Strain relaxation was somewhat higher for the rivet with a compensator.

The presented results concern single riveting processes, so it is not sure that such courses are characteristic for these types of rivets.

\subsection{FEM calculations}

Riveting processes of WP6.2 specimens were analyzed with Finite Element Method. The axisymmetric (Axi) and solid (3D) models were developed. The axisymmetric models described in point 2.3 were scaled and corrected to obtain the geometry of joints with $3,5 \mathrm{~mm}$ rivets. Then, the models were extended to the radius of $50 \mathrm{~mm}$. Only the presence of the central rivet was taken into account in the axisymmetric models (the outer rivets were neglected). Special boundary conditions 
resulting from the use of the special riveting set were modelled. The models consist of about 2600 linear elements and 2900 nodes. Fig. 14 presents the model of the specimen with a brazier rivet.

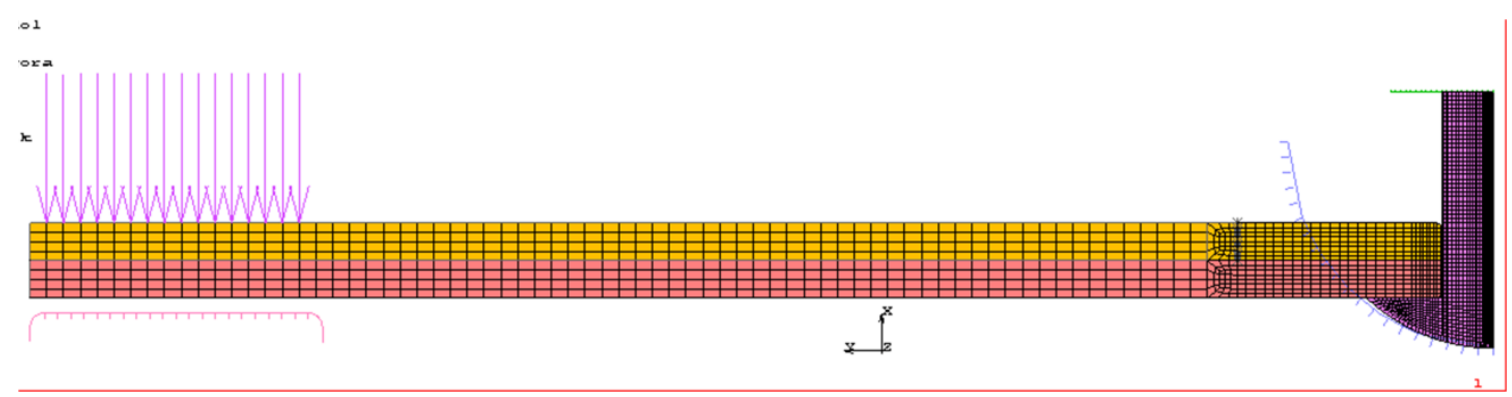

Fig. 14. WP6.2.8.1 specimen FEM model

Forces were applied to the nodes on the sheet surface to model clamping sheets by the fourlegged part (Fig. 13b). The support was modelled as a motionless rigid contact body (curve). At the beginning of the analysis there was a $0,5 \mathrm{~mm}$ slit between the support and sheet surface. The squeezing force value was $15,35 \mathrm{kN}$.

The solid models were developed based on the axisymmetric models. The presence of all rivets was modelled as well as all tool: the hold-on and punch for each rivet as well as the four-legged part (modelled by forces). Only a quarter of specimens were modelled due to symmetry. Because, for the WP6.2.9.1 model (rivet with a compensator), correct results were not obtained, only the WP2.8.1 model (brazier rivet) was presented in the paper. The model (Fig. 15) consist of 95136 linear elements and 109850 nodes.

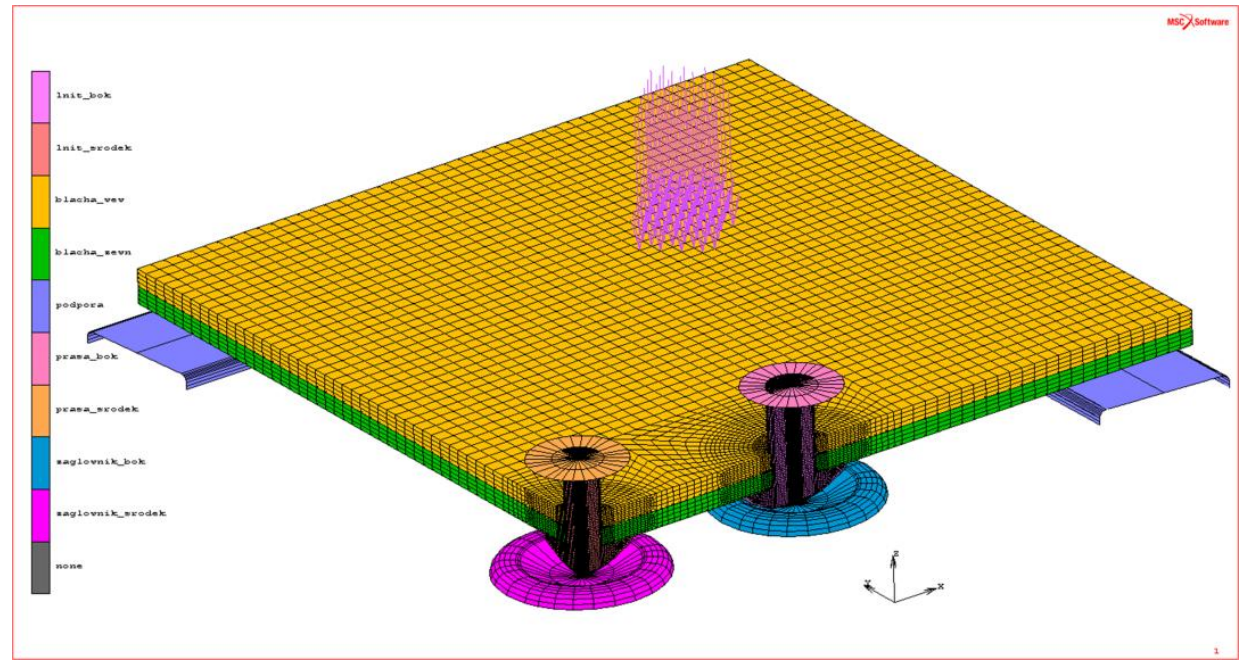

Fig. 15. WP6.2.8.1 specimen solid model 


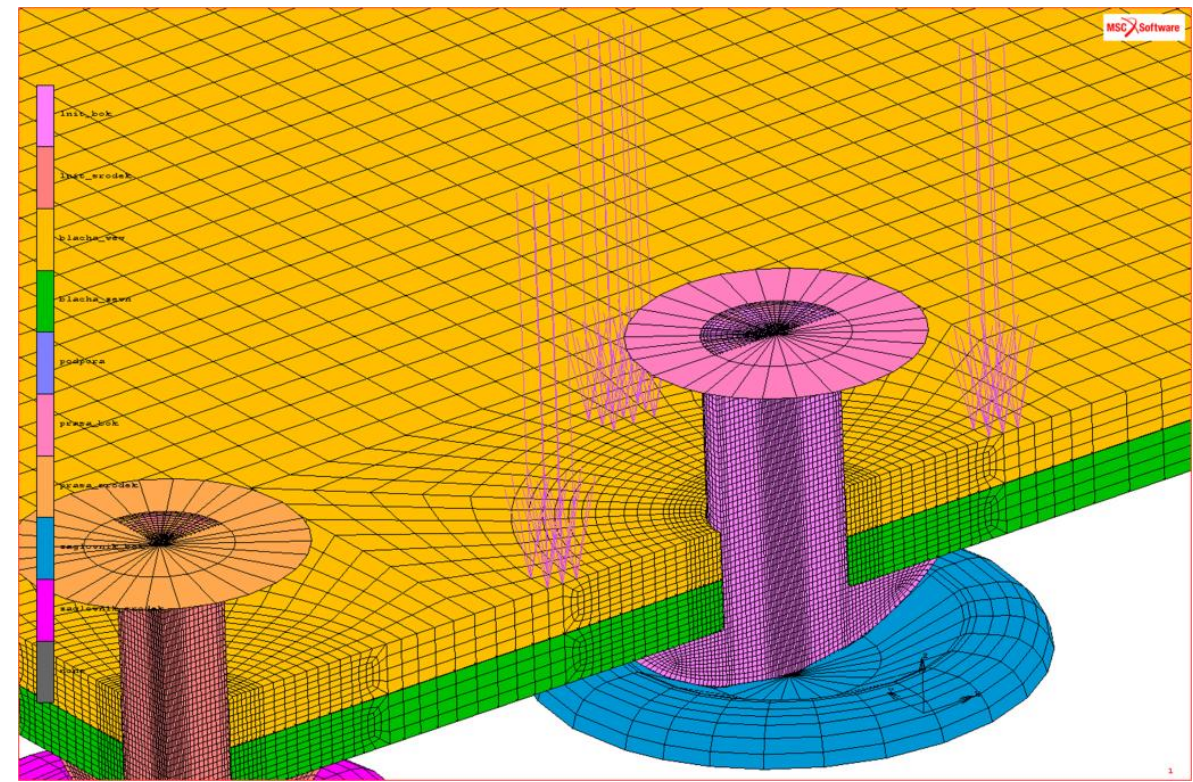

Fig. 16. Camping force near outer rivet

The model consist of four deformable contact bodies (two sheets and two rivets) and five rigid bodies that model the tools (the hold-on, the punch for the central and outer rivet and the support). The material models and friction model were the same as in the axisymmetric models. The rigid surfaces (modelled punches) are controlled by displacement (based on the results of the axisymmetric analyses) instead of force. Clamping parts were modelled by applying forces to the sheet surface. Outer rivets were installed with a standard riveting tool. Forces were applied in three regions near the radius of the clamping sleeve (Fig. 16.). The central rivet was installed with a special riveting set. Clamping forces were applied to the nodes in the area corresponding to the position of the leg (Fig. 15). The values of clamping forces were the same as in the axisymmetric models.

There were two phases of the analysis. At first, the outer rivet were installed. Clamping forces were applied and the punch moved down by $2,75 \mathrm{~mm}$ and returned to its initial position. Afterwards, clamping forces were released and the hold-on moved away. During this stage, all the nodes of the central rivet were fixed in order to limit the number of degrees of freedom (calculation took about one week). During the next phase, the central rivet was installed. The sequence was the same as for the outer rivet.

\section{Results}

The deformations of the models were correct. The pictures of stresses obtained in these calculations were similar to the results of the calculation described in point 2.3. The results were compared with the strain measurements. For the solid model, an increase in strain during the second phase was taken into account. The graphs in Table IX show the plots of strain progress during the riveting process obtained for a particular gauge and for two nodes of the FEM models which are placed closest to this gauge's centre. A series name indicates the type of results (Gauge, Axi-FEM axisymmetric model, 3D-FEM solid model) and the distance between the node and gauge centre. Only the results for gauges no 21, 221 and 11 were presented. 
Experimental and Numerical Study of Strain Progress During and After Riveting Process for Brazier Rivet and Rivet with Compensator - Squeezing Force and Rivet Type Effect

Table IX. Experimental and numerical strain Progress during riveting process

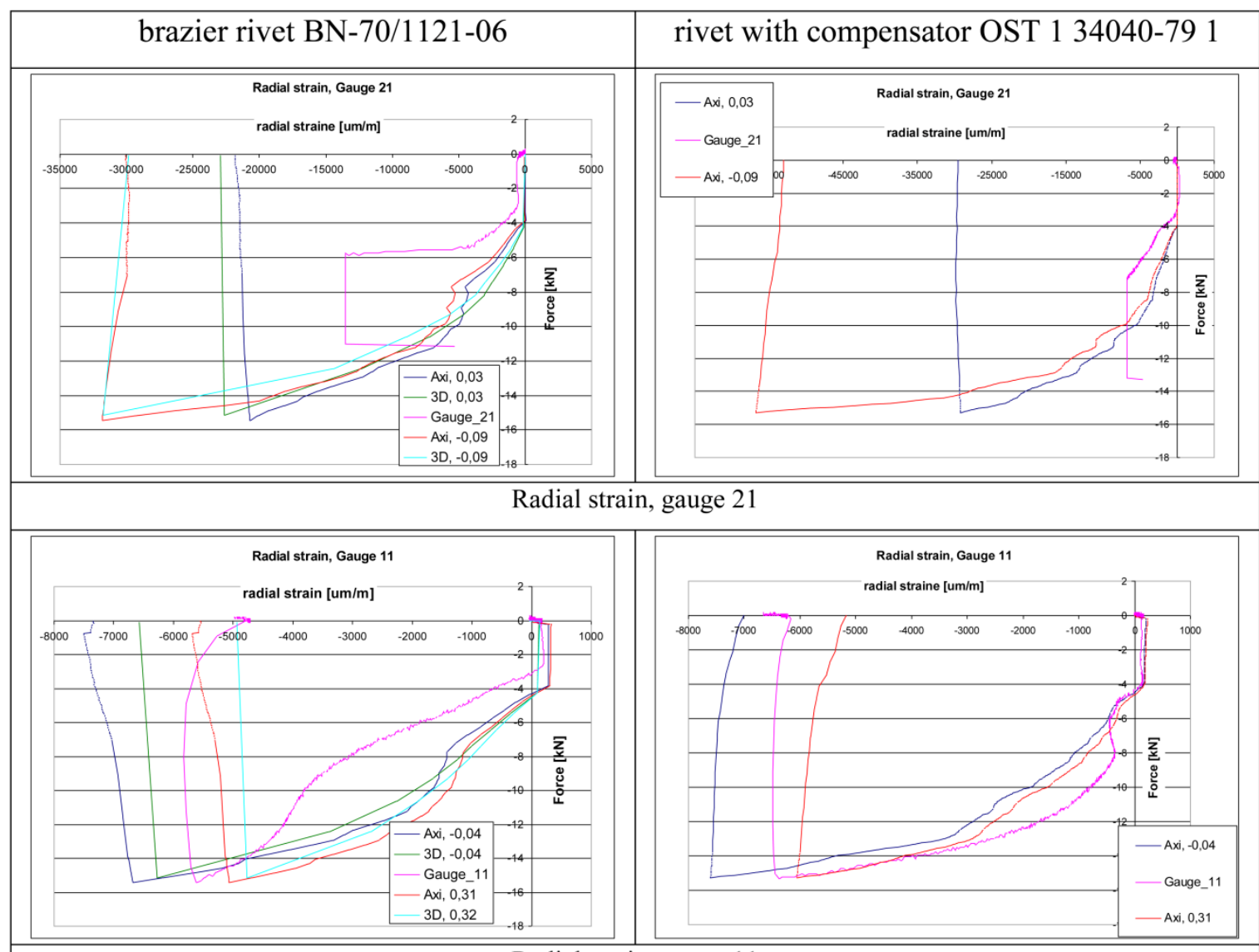

Radial strain, gauge 11

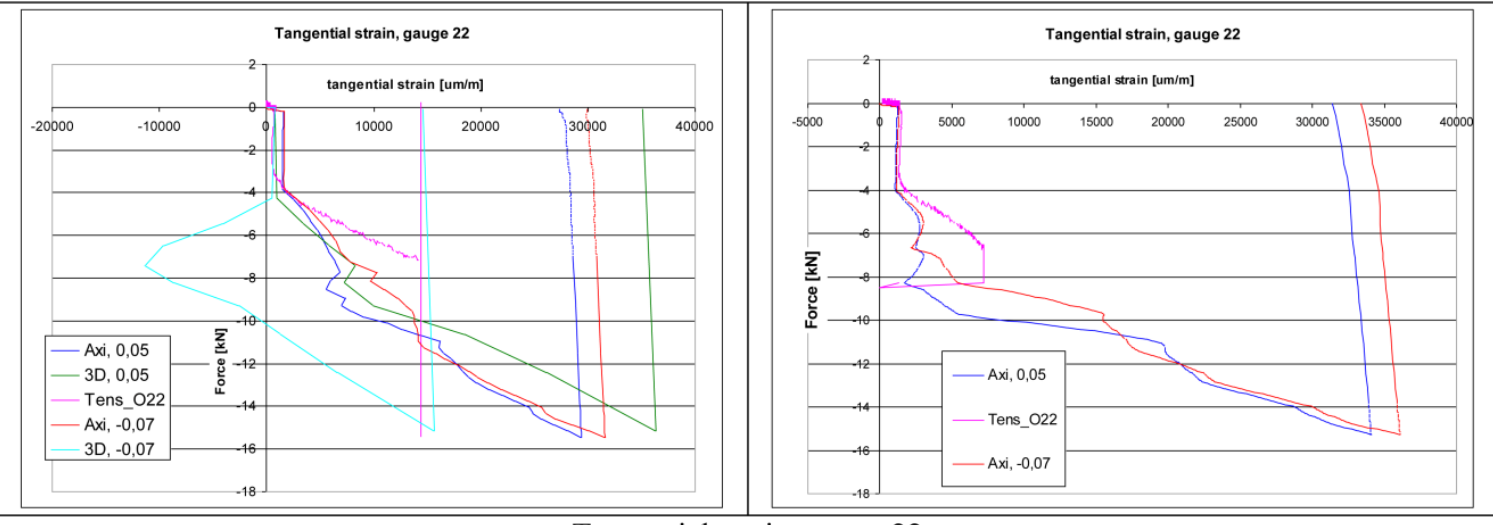

Tangential strain, gauge 22

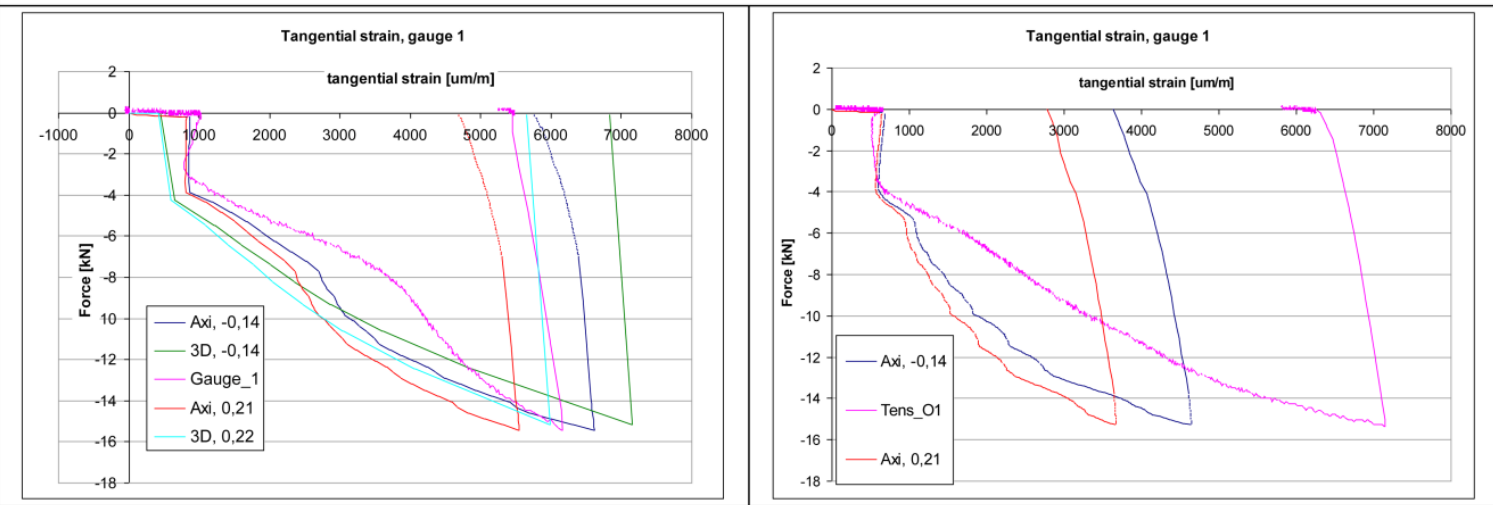

Tangential strain, gauge 1 
The graphs of strain as a function of radial position were collected in Table $\mathrm{X}$. The results for the moments before damage of the micro gauges and after the riveting process were presented. The name of each series indicates the type of the rivet and squeezing force for a particular plot.

Table X. Experimental and numerical strains as a function of radial position

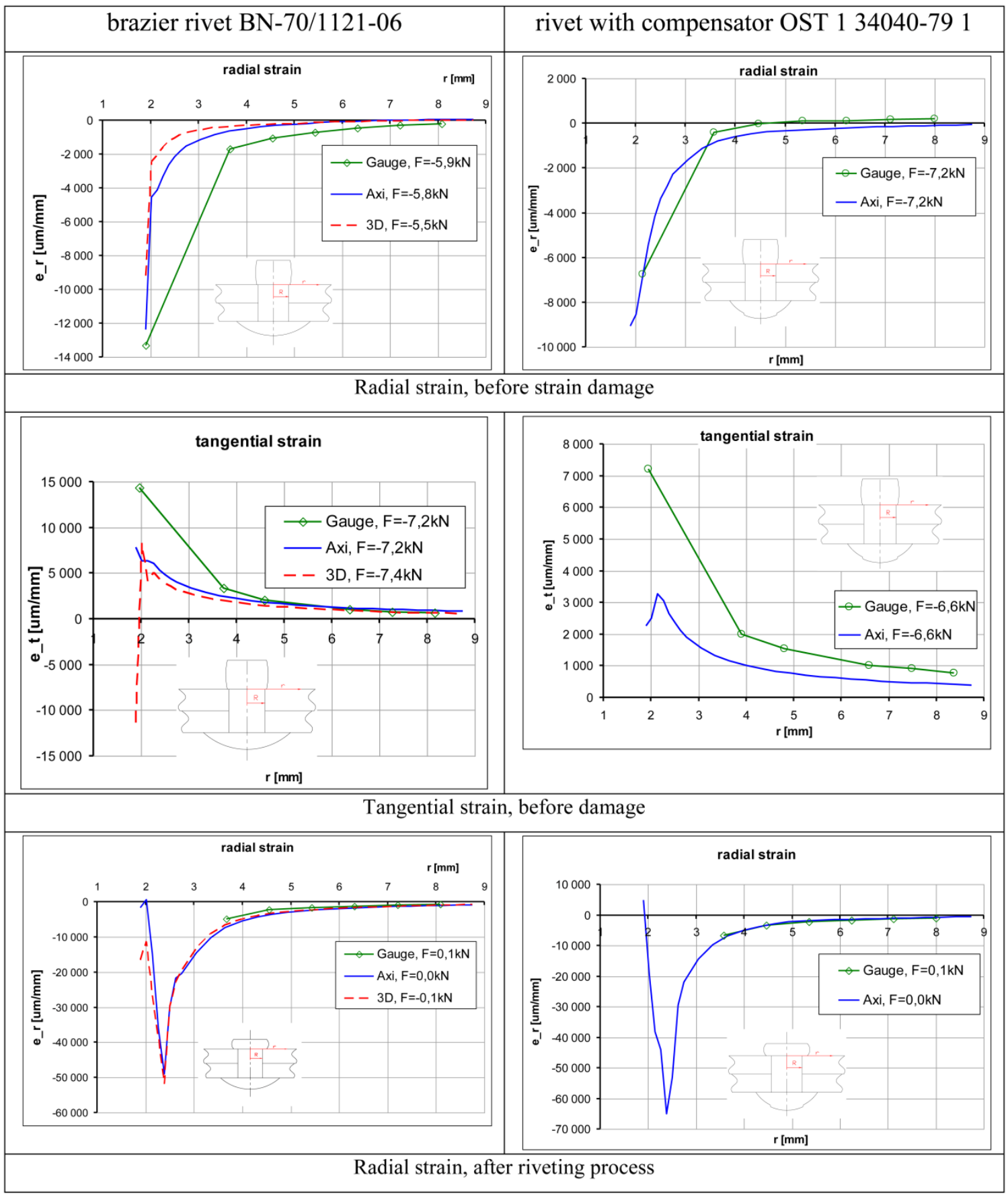




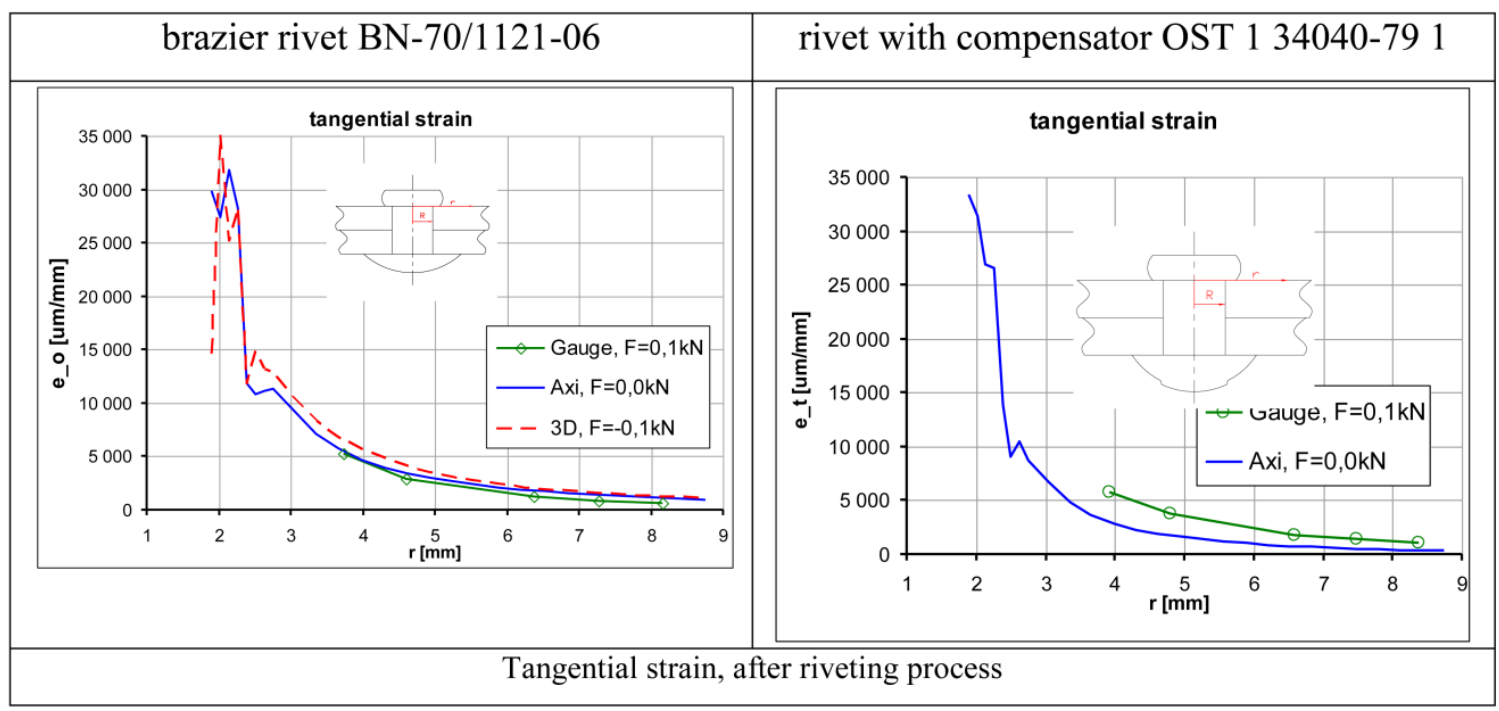

Good correlation with the experiment was obtained for the model of the specimen with a brazier rivet, especially after the riveting process. For the moments before damage of the gauges, slightly lower strains were obtained in the calculations than in the measurements. The calculation results with the axisymmetric and solid models were very similar. The axisymmetric model does not take into account outer rivets and refers to the circular area but the distance between the rivets is 5 diameter (rivets do not interact) and the size of the modelled area is quite large $(100 \mathrm{~mm})$.

In the case of the rivet with a compensator, good correlation with the experiment was obtained for radial stresses. For tangential stresses, the values obtained from the calculation are considerably lower than those obtained from the measurements. This model needs to be refined.

\section{THE EFFECT OF THE RIVET TYPE}

The results of the FEM calculations described above were used to investigate the effect of the rivet type. The results of the FEM calculations for both rivet types were collected in Table XI. The figures present deformations of the models and stresses: equivalent (Huber-Mises-Hencky, HMH), radial and tangential.

\section{Table XI FEM results}

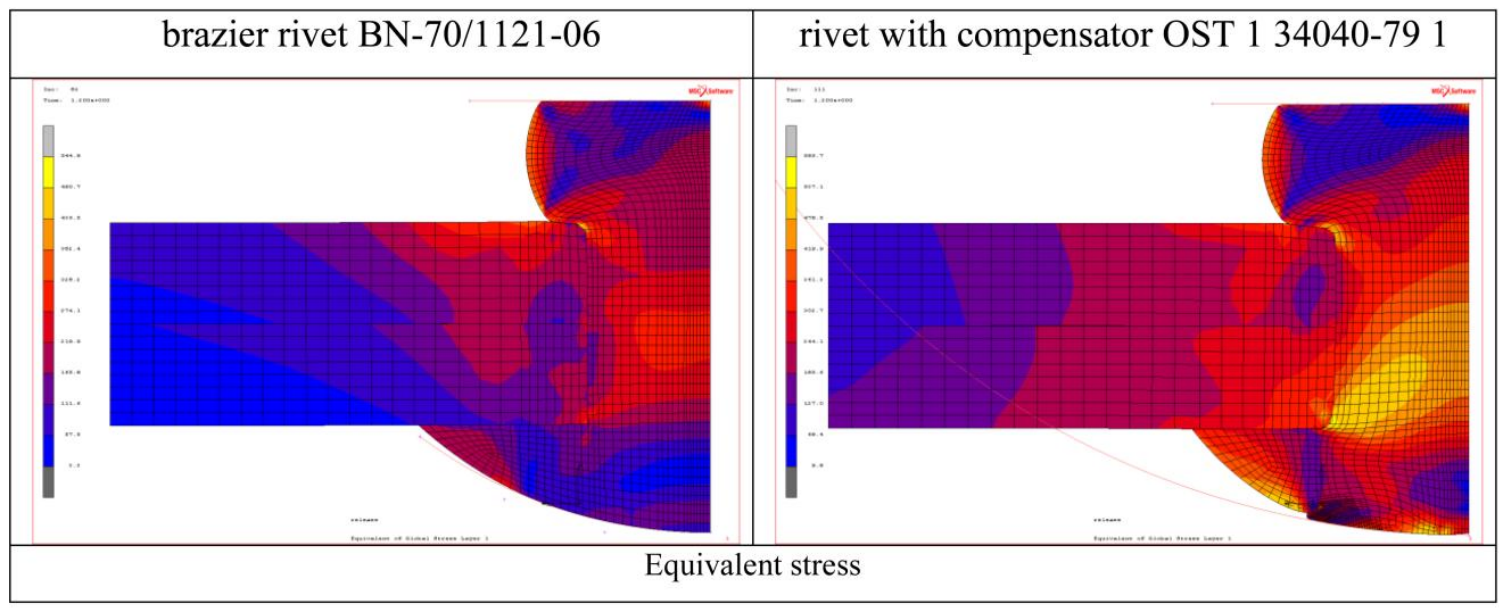




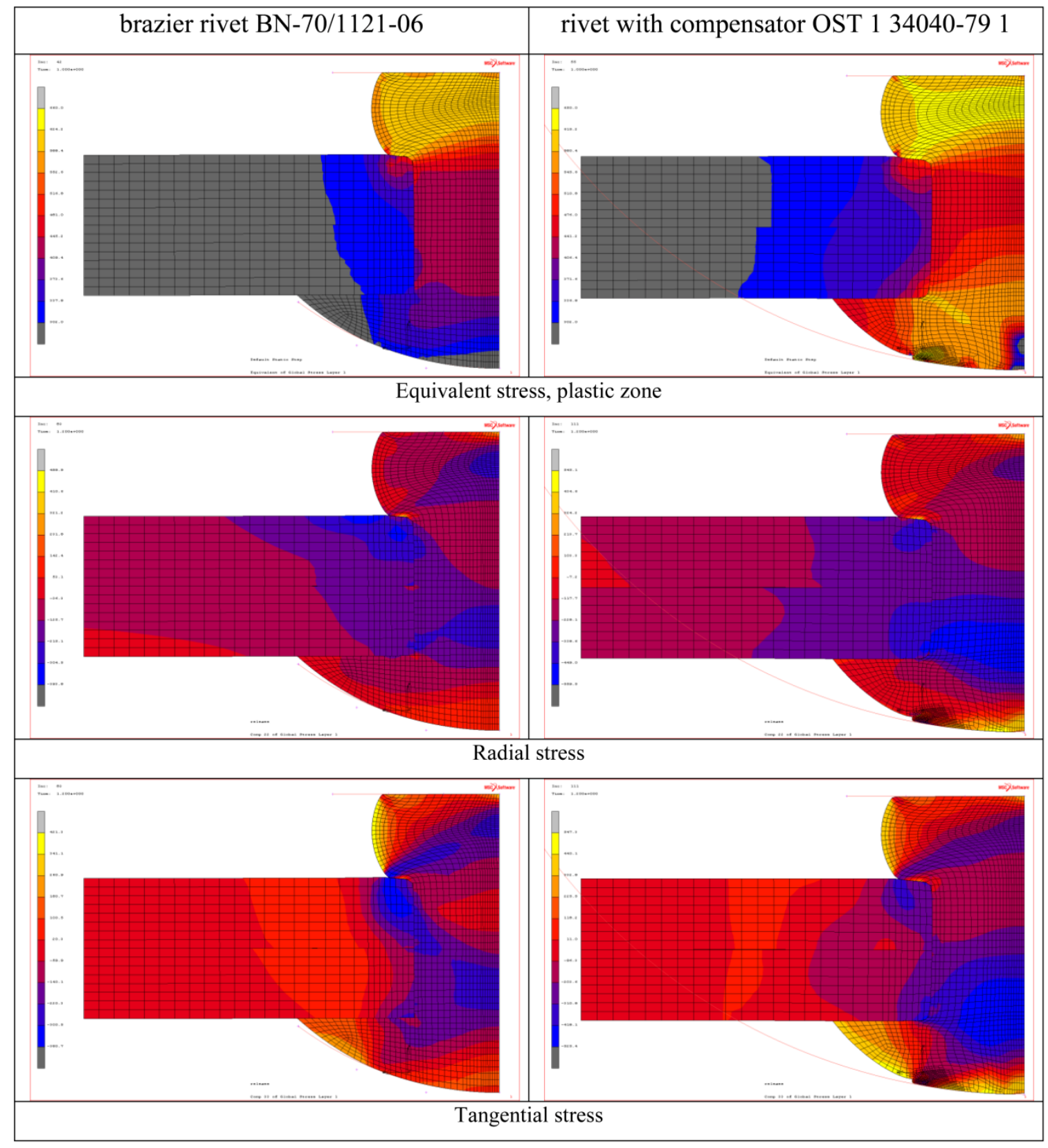

Non-uniform stress distribution along sheet thickness is visible. For the brazier rivet, the highest stress values are near the driven head and the smallest values on the manufactured head side. For the rivet with a compensator, stress distribution is definitely more uniform and stress values are higher. The range of plastic zone is also significantly bigger. Near the rivet hole compression stresses (radial and tangential) occur, which is beneficial from a fatigue point of view as it limits crack nucleation. This is also visible in the graphs gathered in Table IV (near the driven head), Table V (faying surface) and figure 17, where stress distribution at the hole edge was presented. 

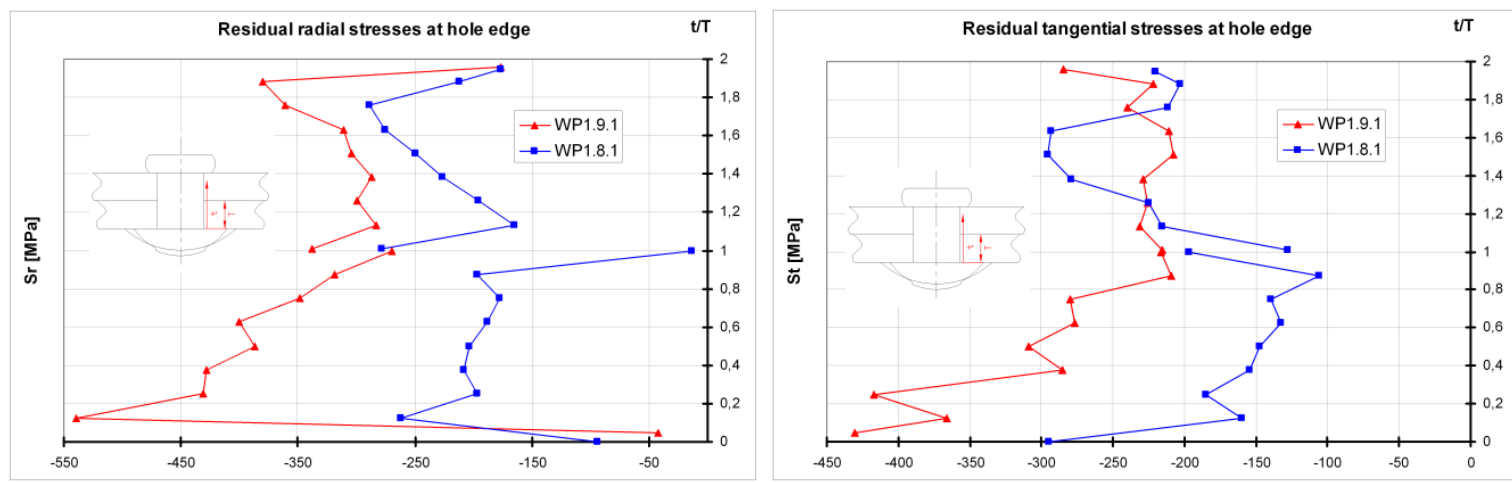

Fig. 17. Stress distribution at the hole edge-FEM calculation

At the very edge of the hole, stress distribution is more uniform for the normal rivet. A higher radial expansion near the manufactured head, caused by a compensator, results in higher compressive stresses. This is particularly important from a fatigue point of view, especially on the faying surface.

\section{SUMMARY}

The paper presents the measurements of strains and stresses around two rivet types, on the sheet surface near the driven head. The experimental results were compared with the FEM calculations. Higher stresses and strains after the riveting process were found for higher squeezing forcees and for rivets with compensators.

The residual stresses existing in the sheet before the riveting process influence the XRD measurements. Further investigations will focus on measuring these stresses and using this information in validation and verification of FEM models. Also, the methodology of XRD measurements around rivets will be developed.

The literature and FEM calculations indicate the presence of high stress and strain gradient near the rivet hole. The XRD measurements covered a region on the boundary or outside the high stress gradient area. This was the reason for the strain gauge measurements. High strain values near the rivet hole were proven. The presence of compressive tangential strains in this region was not experimentally confirmed.

The "S" shaped plot of radial strain for the rivet with a compensator was recorded. Similar shapes of strain plots were presented in paper [7] and [8]. This phenomenon has not been explained so far.

Good correlation of the FEM calculations with the XRD measurements was obtained. Numerical results indicate positive influence of rivet with a compensator on the residual stress system in the sheets after riveting. The area of compressive stress near the rivet is larger in comparison with the normal brazier rivet. The plastic zone is also significantly larger. Stress distribution along sheet thickness is more uniform, except for the area very close to the rivet hole. From a fatigue point of view, higher compressive tangential stresses on the faying surface are particularly important. This might be a reason for higher fatigue life of joints with the rivets with compensators reported in papers [3], [4] and [9].

For the FEM models of the brazier rivet, good correlation with strain gauge measurements was obtained. The calculation results with the axisymmetric and solid models were very similar, with the axisymmetric analysis lasting about 2 minutes and the solid analysis about one week. The model of the specimen with the rivet with a compensator needs to be refined. Also, other FEM models of rivets will be developed. The authors are going to use the FEM models to determine the optimal (from a fatigue point of view) joint geometry and riveting process parameters as well as analyses of tension loaded riveted joints. 


\section{Acknowledgement}

The presented works were carried out under the Eureka project E3496! called IMPERJA. Some results of the research presented were published in [10].

\section{REFERENCES}

[1] Muller, R. (1995). An Experimental and Analytical Investigation on the Fatigue Behaviour of Fuselage Riveted Lap Join, Ph.D. thesis, TU Delft, Netherlands.

[2] Szymczyk, E., Jachimowicz, J. \& Derewońko, A. (2008). Riveting Process Simulation-Upsetting of the Mushroom Rivet. Journal of KONES, 15 (2), 493-502.

[3] Simenz, R.F. \& Steinberg, M.A. (1977). Alloy Needs and Design: the Airframe, In Fundamental Aspects of Structural Alloy Design. Proceeding of the $10^{\text {th }}$ Battelle Colloquium in the Materials Science, Jaffee R. I., Wilcox B. (Ed), A, PLENUM PRESS, New York and London 1977

[4] Klima, Z. (1980). Urceni velikosti nekterych faktoru majicich vliv na unavu nytoveho spojeni, VZLU report no V-1399/80.

[5] ASM Handbook, (1995). Volume 18, Friction, Lubrication, and Wear Technology.

[6] Rans, C.D. (2007). The Role of Rivet Installation on the Fatigue Performance of Riveted Lap Joints (pp. 51-52). PhD thesis, Carleton University Ottawa, Ontario, Canada.

[7] Langrand, B., Patronelli, L., Deletombe, E., Markiewicz, E., Drazétic, P. (2002). Full scale experimental characterisation for riveted joint design. Aerospace Science and Technology, 6(2002), 333-342.

[8] Li, G., Shi, G., Berlinger, N.C. (2006). Study of the Residual Strain in Lap Joint. Journal of Aircraft, 43(4).

[9] Skorupa, M., Skorupa, A., Machniewicz, T., Korbel, A. (2009). An experimental investigation on the fatigue performance of riveted lap joints (pp. 449-473). ICAF 2009, Bridging the Gap between Theory and Operational Practice, Proceedings of the $25^{\text {th }}$ Symposium of the Int. Committee on Aeronautical Fatigue, Rotterdam, The Nederlands, 27-29 May 2009.

[10] Wronicz, W., Kaniowski, J., Korzeniewski, B., Gadalinska, E. (2011). Study of Stress and Strain Field Around the Rivet (pp.277-288). ICAF 2011, Structural Integrity: Influence of Efficiency and Green Imperatives. Proceedings of the $26^{\text {th }}$ Symposium of the Int. Committee on Aeronautical Fatigue, M. Komorowski (Ed.). 1-3 June 2011, Montreal, Canada, Springer. 